\title{
Glutamate Dysregulation in a TauP301L Mouse Model of Alzheimer's Disease
}

Holly C. Hunsberger

West Virginia University

Follow this and additional works at: https://researchrepository.wvu.edu/etd

\section{Recommended Citation}

Hunsberger, Holly C., "Glutamate Dysregulation in a TauP301L Mouse Model of Alzheimer's Disease" (2014). Graduate Theses, Dissertations, and Problem Reports. 667.

https://researchrepository.wvu.edu/etd/667

This Thesis is protected by copyright and/or related rights. It has been brought to you by the The Research Repository @ WVU with permission from the rights-holder(s). You are free to use this Thesis in any way that is permitted by the copyright and related rights legislation that applies to your use. For other uses you must obtain permission from the rights-holder(s) directly, unless additional rights are indicated by a Creative Commons license in the record and/ or on the work itself. This Thesis has been accepted for inclusion in WVU Graduate Theses, Dissertations, and Problem Reports collection by an authorized administrator of The Research Repository @ WVU. For more information, please contact researchrepository@mail.wvu.edu. 
Glutamate Dysregulation in a TauP301L Mouse Model of Alzheimer's Disease

Holly C. Hunsberger

Thesis submitted

to the Eberly College of Arts and Sciences

at West Virginia University

in partial fulfillment of the requirements for the degree of

Master of Science in

Psychology

\author{
Committee \\ Miranda Reed, Ph.D., Chair \\ Melissa Blank, Ph.D. \\ William Wonderlin, Ph.D. \\ Department of Psychology
}

Morgantown, West Virginia
2014

Keywords: glutamate, Alzheimer's disease, tau, hippocampus, memory

Copyright 2014 Holly C. Hunsberger 


\begin{abstract}
Glutamate Dysregulation in a TauP301L Mouse Model of Alzheimer's Disease
\end{abstract}

Holly C. Hunsberger

Individuals at risk for developing Alzheimer's disease (AD) often exhibit neuronal network hyperexcitability, particularly in the $\mathrm{CA} 3$ region of the hippocampus, in the years preceding $\mathrm{AD}$ diagnosis, suggesting that aberrant network activity might contribute to the pathogenesis of $\mathrm{AD}$. Recently, the microtubule-binding protein tau has been implicated in this hyperexcitability. Removal of tau in $\mathrm{AD}$ models overexpressing amyloid- $\beta(\mathrm{A} \beta)$ or non-AD models of epilepsy decreases hyperexcitability and normalizes the excitation/inhibition imbalance. The exact mechanism by which tau produces hyperexcitability remains to be determined, but recent work suggests tau may mediate glutamatergic signaling. Glutamate is the primary excitatory neurotransmitter in the central nervous system and changes in glutamatergic neurotransmission affect the overall activity of neuronal networks. Although beneficial at low levels, high concentrations of extracellular (EC) glutamate can lead to cell death through excessive activation of glutamate receptors, a process referred to as excitotoxicity and linked to several neurodegenerative disorders, including $\mathrm{AD}$. Here, we used a tau mouse model of $\mathrm{AD}$ $(\mathrm{rTg}(\mathrm{TauP} 301 \mathrm{~L}) 4510)$ to examine whether mutant $\mathrm{P} 301 \mathrm{~L}$ tau expression alters synaptic glutamate regulation in the dentate gyrus (DG), CA3 and CA1 regions of the hippocampus. To examine glutamate regulation in vivo, we used an amperometry coupled to ceramic-based microelectrode arrays (MEAs), which allows for measurement of tonic glutamate levels, potassium-evoked glutamate release, and glutamate clearance from the synapse. P301L tau expression did not affect tonic extracellular glutamate levels or clearance from the synapse in any region examined. Similarly, amplitudes of potassium-evoked glutamate release were similar between controls and TauP301L mice in the DG and CA1. However, memory-impaired TauP301L mice exhibited a 7-fold increase in glutamate release in the CA3 region of the hippocampus, and spatial reference memory errors correlated with potassium-evoked glutamate release in the CA3. These data suggest a possible novel mechanism, increased presynaptic glutamate release, by which tau may mediate hyperexcitability. 


\section{Table of Contents}

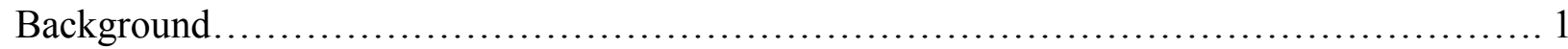

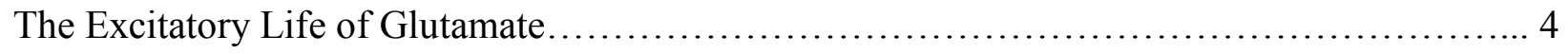

Glutamate's Role in the Pathophysiology of Disease................................. 11

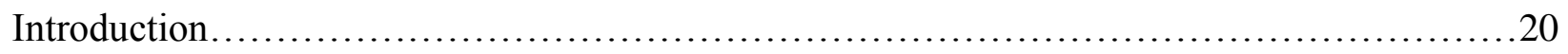

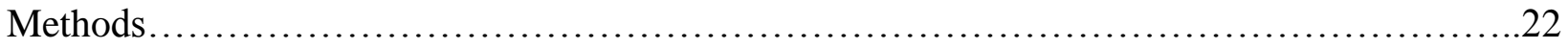

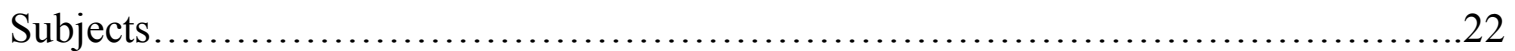

Barnes maze............................................................... 24

Enzyme-based microelectrode arrays........................................... 25

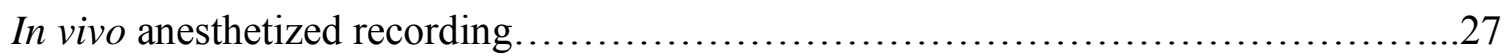

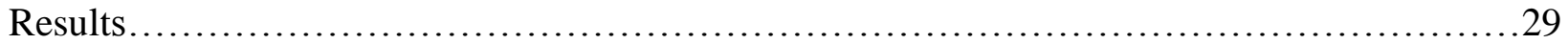

Barnes maze spatial learning and memory...................................29

In vivo microelectrode recordings (tonic, evoked, uptake) ........................29

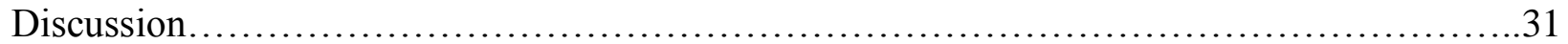

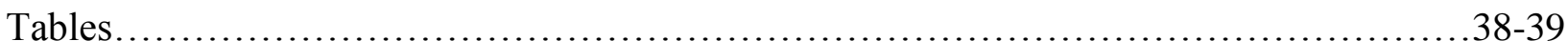

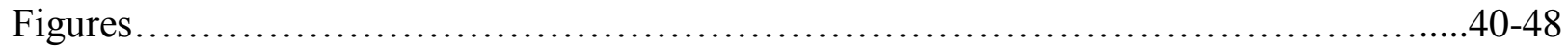

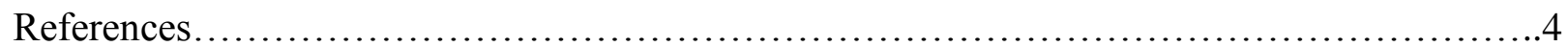




\section{Glutamate Dysregulation in TauP301L Mice}

Alzheimer's disease (AD) affects approximately 5.4 million Americans and is often characterized by progressive memory loss, decline in cognitive skills, and adverse behavioral changes (Thies \& Bleiler, 2013). Biologically, Alzheimer's disease is characterized by an abundance of extracellular amyloid plaques, comprised of aggregates of beta-amyloid (A $\beta)$, and intracellular neurofibrillary tangles containing hyperphosphorylated tau protein (Serrano-Pozo, Frosch, Masliah, \& Hyman, 2011). The third major feature of AD is an alteration of neuronal connections, eventually leading to massive neuron loss throughout the brain. Recent work suggests AD-related pathology begins in particularly vulnerable regions of the brain, including the entorhinal cortex and hippocampus, part of the brain's memory network, before spreading to other cells along the same neural network (de Calignon et al., 2012; Liu et al., 2012; Nath et al., 2012).

Effective regulation of activity in these neural networks is essential. Because both increases and decreases in stimulation can impair neuronal function and survival, neural network dysfunction could contribute directly to the neurodegenerative process (Palop, Chin, \& Mucke, 2006). An early feature in aging, before AD pathology, is the hyperactivity of the memory network, specifically in the CA3 region of the hippocampus. In studies using functional magnetic resonance imaging (fMRI), elevated hippocampal activation is observed in individuals at risk for $\mathrm{AD}$, including cognitively normal carriers of the ApoE4 allele, a known genetic risk factor for AD (Dennis et al., 2010; Filippini et al., 2009; Trivedi et al., 2008), pre-symptomatic carriers of genetic mutations in familial AD (Quiroz et al., 2010), patients with mild cognitive impairment (MCI) (Dickerson et al., 2005; Hamalainen et al., 2007), and asymptomatic and minimally impaired older individuals with amyloid deposition (Sperling et al., 2009). Furthermore, 
longitudinal fMRI assessments of ApoE4 allele carriers indicate that hippocampal overactivation correlates with declines in memory (Bookheimer et al., 2000).

Hippocampal hyperactivity was once believed to serve a compensatory function for deteriorating circuitry by recruiting extra neural resources (Bondi, Houston, Eyler, \& Brown, 2005; Grady et al., 2003; Ward \& Frackowiak, 2003). However, more recent studies show excess activation may contribute directly to memory impairment and AD-related pathology and could represent a therapeutic target. Circumstantial human evidence supports this view; patients with temporal lobe epilepsy, who exhibit substantially elevated neuronal activity, develop amyloid plaques as early as 30 years of age (Mackenzie \& Miller, 1994). Similarly, seizures and epileptiform activity are associated with an early age at onset of cognitive decline and precede or coincide with diagnosis of aMCI or AD (Vossel et al., 2013).

The relation between hyperactivity and memory impairments is more than correlational; treatments targeting excess CA3 activation dose-dependently improved memory performance in memory-impaired aged rats; these same doses had no effect in young rats without memory impairments, suggesting dampening of hippocampal hyperactivity, not merely a global cognitive enhancement, was responsible for the memory improvement in aged rats (Koh, Haberman, Foti, McCown, \& Gallagher, 2010). Furthermore, a reduction in aberrant neural network activity reversed the synaptic and cognitive deficits observed in an $\mathrm{A} \beta$ mouse model of $\mathrm{AD}$ (Sanchez et al., 2012). Evidence for the adverse consequences of hyperexcitability has also been shown in humans; reducing hippocampal CA3 activation in an amnestic MCI group improved memory performance (Bakker et al., 2012). Together, these studies suggest targeting excess hippocampal activity may have therapeutic potential. 
The increased activity of the CA3 could be due to an increase in excitatory glutamatergic signaling or a decrease in inhibitory GABA-ergic signaling, or both. For the purpose of the current project, we will focus on alterations in the glutamatergic system. Glutamate, the major excitatory neurotransmitter, is responsible for many of the brain's functions including cognition and memory (Curtis, Phillis, \& Watkins, 1960; Sheldon \& Robinson, 2007). Glutamate is believed to contribute to hippocampal-dependent learning and memory through long-term potentiation (LTP) (Bliss \& Collingridge, 1993), a long-lasting strengthening in signal transmission between two neurons that results from their synchronous stimulation (Bliss \& Gardner-Medwin, 1973; Bliss \& Lomo, 1973). Although beneficial at low levels, high concentrations of extracellular (EC) glutamate can lead to cell death through excessive activation of glutamate receptors, a process referred to as excitotoxicity (Olney, Price, Samson, \& Labruyere, 1986). Excitotoxicity is linked to several neurodegenerative disorders, including Alzheimer's disease (Hardingham \& Bading, 2010b), and occurs when uncontrolled glutamate release surpasses the capacity of astrocyte clearance mechanisms, leading to an excess of EC glutamate. The following are believed to be the steps fundamental for excitotoxicity: First, excess glutamate accumulates in the synapse, which activates presynaptic ionotropic (Dingledine, 1983; Watkins \& Evans, 1981) and metabotropic receptors (Aleppo et al., 1992; Sacaan \& Schoepp, 1992), leading to further release of glutamate. Glutamate then binds AMPA receptors, leading to depolarization sufficient for magnesium $\left(\mathrm{Mg}^{2+}\right)$ to be expelled from NMDA channels. NMDA channels open, permitting large amounts of calcium $\left(\mathrm{Ca}^{2+}\right)$ to enter. Although this is a physiological process necessary for learning and memory, excess EC glutamate leads to prolonged exposure to glutamate and an excess of intracellular $\mathrm{Ca}^{2+}$ (Choi, 1992; Choi, Koh, \& Peters, 1988; Eimerl \& Schramm, 1994). Thus, the normally tightly regulated $\mathrm{Ca}^{2+}$ levels exceed 
a threshold that leads to activation of several enzymes, including phospholipases, endonucleases, and proteases, such as calpain, that mediate cell death (Annunziato, Cataldi, Pignataro, Secondo, \& Molinaro, 2007). Most studies have examined the link between aberrant neuronal activity and A $\beta$ (Hsia et al., 1999; Mucke et al., 2000; Shankar et al., 2007). The role of tau in mediating neuronal hyperexcitability is less clear but is supported by several recent studies showing that reductions in tau substantially reduce hyperexcitability in $A \beta$ mouse models, induced seizure models, and models of epilepsy (DeVos et al., 2013; Holth et al., 2013; Ittner et al., 2010; Roberson et al., 2007; Roberson et al., 2011). Further examination of the role of tau is warranted. Similarly, though many studies have implicated glutamate in the pathophysiology of AD, most have done so through indirect measures, such as increased signaling of downstream pathways related to excitotoxicity (Hong et al., 2012; Saito, Elce, Hamos, \& Nixon, 1993; Zhang et al., 2010) or in cell culture models (Jamsa et al., 2006; Petroni, Tsai, Mondal, \& George, 2011). Thus, it is essential that an increase in EC glutamate be confirmed in the pathophysiology of AD and the relation to tau pathology identified.

\section{The Excitatory Life of Glutamate}

Because of glutamate's role in LTP and findings of glutamate receptors on almost all neurons (Danbolt, 2001), glutamate is one of the most intensely researched neurotransmitters. This interest is heightened by findings of imbalances in glutamate signaling in many disease processes (see (Sheldon \& Robinson, 2007) for review), including stress (see (Popoli, Yan, McEwen, \& Sanacora, 2012) for review), stroke (Harvey et al., 2011), traumatic brain injury (Schmidt \& Grady, 1993), and several neurodegenerative diseases (Sheldon \& Robinson, 2007), including AD (Scott, Pow, Tannenberg, \& Dodd, 2002). The next sections detail the life of glutamate, from its synthesis, to its packaging into vesicles and release into the synapse, its 
activity once in the synapse, its uptake into astrocytes, and its eventual breakdown. The subsequent sections describe how these steps are altered and can lead to an excess of glutamate signaling, with an emphasis on changes documented in AD. Other diseases are used to highlight alterations not yet examined in $\mathrm{AD}$ but that may represent novel mechanistic links between $\mathrm{AD}$ and glutamate excitotoxicity.

Glutamate synthesis. The synthesis of glutamate, a nonessential amino acid, begins with glucose via the tricarboxylic acid cycle (TCA) (Krebs \& Johnson, 1937). Glucose, located in the astrocyte, then forms citrate, and subsequently synthesis of alpha-ketoglutarate. Glutamate is then metabolized after the conversion of alpha-ketoglutarate by aspartate aminotransferase or glutamate dehydrogenase (Waagepetersen, Qu, Sonnewald, Shimamoto, \& Schousboe, 2005).

Glutamate can also be synthesized from glutamine. In the glutamate-glutamine cycle, glutamate is synaptically released and taken up by surrounding astrocytes, where it is converted to glutamine, a non-neuroexcitatory amino acid, and transferred back to neurons for conversion to glutamate (Norenberg \& Martinez-Hernandez, 1979). The flow of glutamate from neurons to astrocytes is approximately equal to the flow of glutamine from astrocytes to neurons (Rae et al., 2003).

Glutamate release. Glutamate release is mediated by both vesicular and nonvesicular processes (Bollmann, Sakmann, \& Borst, 2000). For vesicular release, glutamate moves into the lumen of the presynaptic vesicles via vesicular glutamate transporters (VGLUTs) (Sudhof, 2004). VGLUTs are located in the presynaptic membrane and package glutamate into vesicles before exocytosis into the synaptic cleft (Takamori, Rhee, Rosenmund, \& Jahn, 2000). Following presynaptic neuronal depolarization, calcium $\left(\mathrm{Ca}^{2+}\right)$ channels open, permitting the influx of $\mathrm{Ca}^{2+}$ and triggering the fusion of VGLUTs with the membrane, resulting in the 
exocytosis of glutamate into the synapse (see (Benarroch, 2010) for review). The three isoforms of VGLUT are VGLUT1, VGLUT2, and VGLUT3. VGLUT1 and VGLUT2 are specific to glutamatergic neurons (Massie, Schallier, Vermoesen, Arckens, \& Michotte, 2010) whereas VGLUT3 is found in cholinergic, serotoninergic, and GABA-ergic neurons (Gras et al., 2002). Though VGLUTs were once believed to be found in both presynaptic neurons and astrocytes, more recent evidence suggests that VGLUTs are not expressed in astrocytes, at least not in the mouse brain (D. Li et al., 2013).

Glutamate can also be released into the synapse via a nonvesicular route that involves the cystine/glutamate antiporter $\left(\mathrm{X}_{\mathrm{c}}^{-}\right)$(Baker, Xi, Shen, Swanson, \& Kalivas, 2002). This antiporter is a plasma membrane-bound, sodium-independent, anionic amino acid transporter (Bannai, 1986) located on astrocytes that functions by exchanging one molecule of extracellular cystine for one molecule of intracellular glutamate (Bannai, 1986).

Glutamate receptors. Once in the extracellular space, glutamate can bind to ionotropic (iGluR) or metabotropic (mGluR) receptors (see (Kew \& Kemp, 2005; Schoepp, 2001) for review). The iGLuRs include: N-methyl-D-aspartate (NMDA), $\alpha$-amino-3-hydroxy-5methylisoxazole-4-propionic acid (AMPA), and kainic acid (KA) (Nakanishi, 1992). NMDA receptors (NMDARs) are ligand-gated ion channels that constitute a majority of glutamate receptors in the mammalian brain and differ from AMPA and KA receptors in three ways. First, NMDARs are unique in that they require two obligatory co-agonists (Johnson \& Ascher, 1987; Kleckner \& Dingledine, 1988). Both glutamate and glycine binding sites must be occupied for NMDAR activation to occur (Johnson \& Ascher, 1987; Kleckner \& Dingledine, 1988). Second, NMDARs are not only ligand-gated, but also voltage-gated (Nowak, Bregestovski, Ascher, Herbet, \& Prochiantz, 1984). At resting potential, the channel is blocked by $\mathrm{Mg}^{2+}$ even if the co- 
agonists are bound to the receptor. Activation of AMPA- or KA- receptors, which depolarizes the neuron, is required to relieve the $\mathrm{Mg}^{2+}$ blockade. Because NMDARs require concomitant presynaptic (release of glutamate) and postsynaptic (depolarization) activities, NMDARs detect the coincidence of two events and are sometimes referred to as coincidence detectors. In addition, NMDARs have a higher permeability to $\mathrm{Ca}^{2+}$ than AMPA- or KA- receptors (Dingledine, 1983; MacDermott, Mayer, Westbrook, Smith, \& Barker, 1986). The increased influx of $\mathrm{Ca}^{2+}$ triggers secondary messenger systems leading to the establishment of LTP, a process believed to underlie learning and memory (Bliss \& Collingridge, 1993). However, overactivation of NMDARs leads to an excess of intracellular $\mathrm{Ca}^{2+}$, which initiates a series of events leading to cell death (Choi, 1987; Choi et al., 1988; Choi, Maulucci-Gedde, \& Kriegstein, 1987).

NMDARs have seven subunits (NR1, NR2A-D, and NR3A-B) with NR1 and NR3 binding to glycine (Nilsson, Duan, Mo-Boquist, Benedikz, \& Sundstrom, 2007) and NR2 binding to glutamate (Kutsuwada et al., 1992). NMDARs are heteromeric complexes containing NR1 subunits and a combination of NR2 and/or NR3 subunits. Because NR3A is restricted to expression during development (Al-Hallaq et al., 2002) and NR3B is restricted to brain regions not involved in early stages of $\mathrm{AD}$ [i.e., the somatic motor neurons of the brainstem and spinal cord (Fukaya, Hayashi, \& Watanabe, 2005)], focus in the next section will be given to NR1/NR2 complexes. Likewise, NR1/NR2 complexes play an important role in learning and memory (Cao et al., 2007), as well as excitotoxicity (von Engelhardt et al., 2007), and are abundantly located in the hippocampus, one of the first regions affected in AD (Braak \& Braak, 1998; Du et al., 2004; van de Pol et al., 2007). 
AMPA and KA are agonized by AMPA and kainate, respectively and are more permeable to sodium $\left(\mathrm{Na}^{+}\right)$and potassium $\left(\mathrm{K}^{+}\right)$than $\mathrm{Ca}^{2+}$ (Burnashev et al., 1992; van de Pol et al., 2007). AMPA and KA receptors have an immediate response upon binding of glutamate, and the influx of $\mathrm{Na}^{+}$causes depolarization, leading to the removal of the $\mathrm{Mg}^{2+}$ block of NMDARs (Chittajallu et al., 1996; Tang, Dichter, \& Morad, 1989). AMPA receptors are composed of a four-subunit family (GluR1-4) (Hollmann, Hartley, \& Heinemann, 1991; Keinanen et al., 1990). GluR1, 3, and 4 allow $\mathrm{Ca}^{2+}$ permeability, whereas the GluR2 removes this permeability (Hollmann, Hartley, \& Heinemann, 1991). KA receptors have subunits ranging from GLuR5-7, also referred to as GluK5-7 or KA1-2 (Bettler et al., 1990; Bettler et al., 1992; Egebjerg, Bettler, Hermans-Borgmeyer, \& Heinemann, 1991; Herb et al., 1992; Werner, Voigt, Keinanen, Wisden, \& Seeburg, 1991). Of the two, AMPARs are the more commonly studied in relation to AD.

The mGLuRs are G-protein coupled and subdivided into three groups: Group I, II, and III (Masu, Tanabe, Tsuchida, Shigemoto, \& Nakanishi, 1991). Of the Group I mGLuRs, mGluR1s are located pre- and post-synaptically, while mGluR5s are located post-synaptically and on glia. Both play a role in synaptic plasticity, though mGluR1s are associated with both LTP and LTD, whereas mGluR5s are associated only with LTD (Charpak, Gahwiler, Do, \& Knopfel, 1990; Desai \& Conn, 1991; Desai, Smith, \& Conn, 1992). Though both Group I mGluR subtypes are found in the hippocampus, the subtypes are distributed differentially in the cornu ammonis (CA) 1 and 3 pyramidal cells of the hippocampus; both mGluR1 and mGluR5 cells are found in CA3 cells, whereas CA1 cells only express mGluR5s (Lujan, Nusser, Roberts, Shigemoto, \& Somogyi, 1996; Shigemoto et al., 1993).

Group II mGLuRs (mGLuR2 and 3) are located primarily at the pre-synapse of glutamate neurons, where they act as a negative feedback system, though mGluR3s are also located post- 
synaptically and on glial cells. These receptors, particularly the mGluR2s, act to inhibit glutamate release upon stimulation (Yokoi et al., 1996). Because spillover of glutamate is necessary for activation of these receptors (Scanziani, Salin, Vogt, Malenka, \& Nicoll, 1997), they appear to serve a protective role. Until recently, mGluR3 function was thought to be associated with GABA expression only (Ghose et al., 1997). However, in 2003 it was shown that activation of astrocystic mGluR3s resulted in increased expression of glutamate transporters (GLAST and GLT-1), while knockout of mGluR3s resulted in a down regulation of GLAST and GLT-1 expression (Lyon, Kew, Corti, Harrison, \& Burnet, 2008). Together, these studies suggest mGluR3s may regulate EC glutamate via changes in transporter expression (Aronica et al., 2003). Furthermore, in 2005 mGluR3s were found to be required for LTD in the hippocampus (Poschel, Wroblewska, Heinemann, \& Manahan-Vaughan, 2005).

Group III mGLuRs (mGLuR 4, 6, 7, and 8), located on both the pre and post synapse, primarily act to negatively modulate glutamate transmission (Kinoshita, Shigemoto, Ohishi, van der Putten, \& Mizuno, 1998; Semyanov \& Kullmann, 2000). mGLuRs 4 and 7 negatively modulate glutamate transmission in the hippocampus (Semyanov \& Kullmann, 2000) while mGluRs 4 and 8 are located presynaptically in the CA3 region of the hippocampus and decrease glutamate release following activation (Sansig et al., 2001; Semyanov \& Kullmann, 2000). mGLuRs 7, however, have a lower affinity for glutamate than other mGLuRs, suggesting that these receptors may only become active if glutamate levels are high and may serve as a check for glutamate excitotoxicity (Sansig et al., 2001). mGLuRs 6 are only found in the retina and act to inhibit cell hyperpolarization (Tian \& Kammermeier, 2006). These receptors are directly involved in glutamate transmission in the visual sensory system. 
Glutamate uptake. For proper neurological functioning, it is essential that glutamate levels in the extracellular space remain low. Because there are no enzymes to degrade glutamate, the only way to end glutamate signaling is through its uptake via receptors known as excitatory amino acid transporters (EAATs) (Danbolt, 2001). The EAATs are ATP-dependent transporters, meaning they require energy in the form of ATP to remove glutamate from the synapse. This is important because a depletion of oxygen, such as during a stroke (Lo, Dalkara, \& Moskowitz, 2003), can lead to a decrease in ATP, resulting in a decrease in glutamate uptake and an excess of EC glutamate.

There are five known EAATs (Danbolt, 2001). Only EAAT1 and EAAT2, also referred to as GLAST and GLT-1 respectively, are expressed in rodent brains (Storck, Schulte, Hofmann, \& Stoffel, 1992). GLAST and GLT-1 are primarily responsible for glutamate uptake and are located on astrocytes (Lehre, Davanger, \& Danbolt, 1997; Lehre, Levy, Ottersen, StormMathisen, \& Danbolt, 1995). EAAT3 is present on postsynaptic neurons in the in the CA1 region of the hippocampus and the granular layer of the dentate gyrus, and its uptake of glutamate is sodium dependent (Crino et al., 2002). While GLAST and GLT-1 are found only in the brain, EAAT3 can also be found in the intestines, kidney, liver, and heart (Kanai \& Hediger, 1992). CNS expression of EAAT3 is relatively low compared to that of GLT and GLAST (Haugeto et al., 1996). EAAT4 is expressed primarily in the cerebellum purkinje cells, while EAAT5 is found in retinal neurons and is involved in visual processing (Arriza, Eliasof, Kavanaugh, \& Amara, 1997).

Glutamate degradation. Following astrocytic uptake, glutamate is converted into glutamine via the glutamine synthetase pathway (Norenberg \& Martinez-Hernandez, 1979). Astrocytes dispose of glutamate by converting it to glutamine (Martinez-Hernandez, Bell, \& 
Norenberg, 1977) or alpha-ketoglutarate (McKenna, Sonnewald, Huang, Stevenson, \& Zielke, 1996) through amination processes. Glutamine is then released into the extracellular space where it is taken into presynaptic terminals via sodium coupled neutral amino acid transporters (SNAT3 and SN1) (Boulland et al., 2002). Conversion of glutamate to glutamine before release into the extracellular space prevents glutamate-induced neuronal depolarization (Danbolt, 2001; McKenna \& Sonnewald, 2005)). Following presynaptic uptake, glutamine is converted into glutamate as described in the glutamate synthesis section (Ramaharobandro, Borg, Mandel, \& Mark, 1982).

\section{Glutamate's Role in the Pathophysiology of Disease}

Although glutamate is essential for learning and memory, excess glutamate in the synapse can cause overexcitation of postsynaptic receptors, eventually leading to neuronal death through apoptosis (Olney \& de Gubareff, 1978). This process is termed excitotoxicity and is observed in many disease processes (Olney, 1969). The following section describes ways in which EC glutamate can accumulate to reach pathological levels. Though focus will be given to glutamate alterations observed in $\mathrm{AD}$, glutamate dysregulation in other diseases will be used to highlight potentially novel, as yet unexamined, mechanisms underlying excitotoxicity pathology in $\mathrm{AD}$.

Alterations in glutamate synthesis. The glutamate/glutamine pathway provides a path to rapidly recycle glutamate, but alterations in glutamate synthesis can lead to changes in glutamate levels (Lieth, LaNoue, Antonetti, \& Ratz, 2000). For example, diabetes reduces glutamine synthetase (GS), an enzyme that converts glutamate to glutamine, leading to glutamate accumulation (Lieth et al., 2000). Individuals with schizophrenia also exhibit decreased levels of GS and elevated glutamine synthetase-like protein (GSLP) and glutamate dehydrogenase 
enzymes (GDH) (Burbaeva et al., 2003). It is not yet known why GSLP or GDH are elevated or if these findings suggest elevated or decreased glutamate levels, as evidence suggests both hyperand hypo- function of glutamate in the etiology of schizophrenia (see (Krystal et al., 1999) for review).

Decreased GS levels have also been found in biopsies of human AD brains, and decreased levels of GDH have been found in other neurodegenerative disorders (Plaitakis, Flessas, Natsiou, \& Shashidharan, 1993; Robinson, 2000). The possible role of GS in AD etiology is still unclear, but blockade of GS prevents memory consolidation (Gibbs et al., 1996). Likewise, GS levels decline with age (Hensley et al., 1994; Smith et al., 1991). Given that age is the greatest risk factor for AD, age-related decreases in GS might be one of many ways in which aging increases the risk for AD.

Alterations in glutamate release. Another way in which glutamate can reach pathological levels in the extracellular space includes increases in the packaging of glutamate into vesicles using VGLUTs. VGLUT protein expression levels correspond to the strength of presynaptic glutamate levels (Massie et al., 2010) and increased VGLUT expression causes excitotoxic neurodegeneration (Daniels, Miller, \& DiAntonio, 2011). In a rodent model of Parkinson's disease, another neurodegenerative disease associated with excitotoxicity (Surmeier, 2007), VGLUT1 expression is increased (Massie et al., 2010). Although alterations in VGLUT expression have not been reported in the AD literature to date, preliminary data from the Reed lab (Figure 1) shows increased VGLUT1 expression in mice expressing human tau carrying the proline to leucine mutation at the $301^{\text {st }}$ amino acid (rTg(TauP301L)4510, herein called TauP301L). These mice exhibit neurofibrillary tangles, neurodegeneration and progressive memory decline (Ramsden et al., 2005; Santacruz et al., 2005) and are commonly used to study 
the role of tau pathology in AD. These are also the mice used in the current study and will be described in greater detail below.

The cystine-glutamate antiporter $\left(\mathrm{X}_{\mathrm{c}}^{-}\right)$may also be responsible for excitotoxic effects. Increased expression of the $\mathrm{X}_{\mathrm{c}}{ }^{-}$system leads to an increase in glutamate release (Pampliega et al., 2011) and is observed in several diseases associated with neurodegeneration and glutamate excitotoxicity. For example, $\mathrm{X}_{\mathrm{c}}{ }^{-}$expression is increased in multiple sclerosis (Pampliega et al., 2011), hypoxic neuronal injury (Fogal, Li, Lobner, McCullough, \& Hewett, 2007), Parkinson's disease (Massie et al., 2008), gliomas (Savaskan et al., 2008), and around plaques in AD mouse models (Qin et al., 2006).

Alterations in glutamate receptors. As EC glutamate levels increase, differential activation of NMDARs occurs. At low levels, glutamate primarily activates synaptic NMDARs (see (Kew \& Kemp, 2005; Schoepp, 2001) for review), which predominantly contain the NR2A subunit (Anson, Chen, Wyllie, Colquhoun, \& Schoepfer, 1998). Synaptic NMDARs mediate neuronal survival and resistance to trauma via their anti-apoptotic and antioxidant effects (Hardingham, 2006; Hetman \& Kharebava, 2006; Leveille et al., 2010). In contrast, extrasynaptic NMDARs, located on the spine neck, dendritic shaft, or soma (Petralia, Sans, Wang, \& Wenthold, 2005), are activated only by high glutamate concentrations (Hardingham, 2006) or glutamate released from astrocytes (Bezzi et al., 2004). Activation of extrasynaptic NMDARs (predominately containing the NR2B subunit) is associated with neurotoxicity by stimulating cell death pathways (Hardingham, Fukunaga, \& Bading, 2002; Thomas, Grandy, Gerhardt, \& Glaser, 2009). The pathways triggered by extrasynaptic NMDARs are often in direct opposition to those triggered by synaptic NMDARs (Ivanov et al., 2006). One particularly relevant example includes the differential effects on CREB (cyclic-AMP response element 
binding protein), a transcription factor essential for the conversion of short-term memory to longterm memory (Brightwell, Gallagher, \& Colombo, 2004; Deisseroth, Bito, \& Tsien, 1996; Impey et al., 1998). Synaptic NMDARs activate CREB (Hardingham et al., 2002), whereas extrasynaptic NMDARs inactivate CREB, and this inactivation dominates over the effects of synaptic NMDAR activation (Hardingham \& Bading, 2010a; Hardingham et al., 2002; Papadia et al., 2008). The differential effects on CREB suggest one way in which excess EC glutamate may contribute to memory deficits.

Increased activation of extrasynaptic NMDARs may also mediate tau pathology in AD. Increased activation of NR2B-containing receptors induces tau phosphorylation, while blockade of NR2B receptors prevents this phosphorylation (Allyson, Dontigny, Auberson, Cyr, \& Massicotte, 2010). Likewise, blockade of extrasynaptic NR2B receptors abolishes tau-mediated cytotoxicity in a cell culture system (Amadoro et al., 2006). Memantine, used to treat AD, preferentially blocks extrasynaptic NMDARs at low doses, while sparing normal synaptic activity (Xia, Chen, Zhang, \& Lipton, 2010). Memantine treatment reduces tau phosphorylation (Song, Rauw, Baker, \& Kar, 2008) and excitotoxicity (Okamoto et al., 2009) while increasing memory functioning (Parsons, Stoffler, \& Danysz, 2007). We hypothesize that in our TauP301L mouse model, a self-propagating, feed-forward loop of toxicity might exist in which the increased expression of VGLUT1 (Figure 1) leads to an increase in EC glutamate and increased activation of extrasynaptic NMDARs. This increased activation is predicted to then exacerbate tau phosphorylation.

mGLuRs may also receptors mediate excitotoxicity. For example, activation of Group I mGluRs (predominantly mGluR5) activate protein kinase C (PKC), which enhances NMDARmediated neuronal toxicity (Bruno et al., 1995) by creating longer lasting calcium channel 
openings (Wagey, Hu, Pelech, Raymond, \& Krieger, 2001). Blocking of group I mGluRs reduces neurological deficits produced by glutamate release in traumatic brain injury (Gong, Delahunty, Hamm, \& Lyeth, 1995). mGluR1 knockout mice, however, exhibit learning and LTP deficits (Gil-Sanz, Delgado-Garcia, Fairen, \& Gruart, 2008), suggesting some activity at these sites is needed for normal cognitive functioning.

Both Group II and III act primarily through negative feedback systems such that when activated further glutamate release is suppressed, but their role excitotoxicity is controversial. While some believe group II mGluRs to be neuroprotective when activated (Movsesyan \& Faden, 2006), others have shown that group II activation does not prevent neuronal excitotoxicity (Behrens et al., 1999).

Alterations in glutamate uptake. Decreases in glutamate transporters can also lead to increased EC glutamate levels. EAATs are significant in that they control and limit glutamate spillover between adjacent synapses (Diamond, 2001). EAAT abnormalities may arise through various mechanisms, including alterations in trafficking, phosphorylation or cleavage of EAATs, alterations in mRNA splicing, increases in EAAT turnover, or reductions in transport capacity (see (Maragakis \& Rothstein, 2004) for review). One mechanism particularly relevant to neurodegenerative diseases includes inhibition of EAATs in response to oxidative damage (Trotti, Rolfs, Danbolt, Brown, \& Hediger, 1999), a common problem in many neurodegenerative diseases (Uttara, Singh, Zamboni, \& Mahajan, 2009).

Decreases in EAATs have been reported in an A $\beta$ mouse model of AD (Masliah et al., 2000), as well as in mice expressing mutant tau in astrocytes (Forman et al., 2005). Interestingly, the decrease in EAATs occurred prior to tau accumulation (Forman et al., 2005), suggesting alterations in EC glutamate may precede tau pathology. With normal aging, transporter 
expression declines, but this decrease is exacerbated in AD patients (Zoia et al., 2004).

Decreases in EAATs are found in the midfrontal cortex of AD patients (Li, Mallory, Alford, Tanaka, \& Masliah, 1997) but not in the cingulate and inferior temporal gyri (Beckstrom et al., 1999). Likewise, individuals with amyotrophic lateral sclerosis (ALS), another neurodegenerative disorder, also exhibit decreases in glutamate transporters and increases in EC glutamate (Rothstein et al., 1996).

\section{To Be Resolved.}

$\mathrm{AD}$ is part of a group of neurodegenerative diseases collectively known as tauopathies in which tau, a microtubule-associated protein responsible for stabilizing microtubules, becomes abnormally hyperphosphorylated. Once hyperphosphorylated, tau no longer binds to tubulin nor promotes microtubule assembly, and mislocalizes from axons to the somato-dendritic compartment, where it accumulates to form insoluble tangles (see (Iqbal, Liu, Gong, \& GrundkeIqbal, 2010) for review). Because tau hyperphosphorylation precedes tangle formation, identifying and therapeutically targeting factors that increase tau hyperphosphorylation are of considerable interest. Previous work (e.g., (Allyson et al., 2010; Hardingham et al., 2002; Thomas et al., 2009)) suggests alterations in glutamate signaling represent one such target. Determining whether tau can disrupt glutamate signaling, in the absence of A $\beta$ pathology, represents a first step towards this ultimate goal. To determine the role of tau in glutamate dysregulation, we used TauP301L mice. Though these mice eventually exhibit age-dependent tangles, cognitive decline, and neuron loss (Ramsden et al., 2005; Santacruz et al., 2005), we examined glutamate dysregulation at a time point prior to such changes because electrophysiological hyperexcitability (e.g., an increased action potential firing rate) is prominent in these mice prior to tangle deposition or neuronal death (Crimins, Rocher, \& Luebke, 2012). 
In Alzheimer's disease, the hippocampus is one of the first regions affected (Braak \& Braak, 1998; Du et al., 2004; Szapiro et al., 2002; van de Pol et al., 2007). This increased vulnerability is related in part to the high concentration of glutamate receptors (Greenamyre \& Young, 1989) that mediate communication of the trisynaptic circuit of the hippocampus. This circuit is composed of three distinct subregions (Figure 2), the dentate gyrus (DG), cornuammonis 3 (CA3) and cornuammonis 1 (CA1). Although the pathway works as a circuit, each subregion has unique characteristics, including differences in synaptic connectivity, surface expression of glutamate receptors, gene expression profiles, and levels of glutamate release and clearance following KCl-evoked release (Gegelashvili, Danbolt, \& Schousboe, 1997; Greene, Borges, \& Dingledine, 2009; N. R. Wilson et al., 2005). Below, a rationale for examining each of these three regions separately is made.

The entorhinal cortex (EC), which is the first region affected in $\mathrm{AD}$, projects to the $\mathrm{DG}$. In patients with $\mathrm{AD}$, interruption of the granule cells from the entorhinal cortex to the $\mathrm{DG}$ impairs learning and memory (Gomez-Isla et al., 1996; West \& Slomianka, 1998). Second, though $\mathrm{A} \beta$ deposits in the $\mathrm{CA} 1$ region of the hippocampus during Braak stage 1 and 2 of $\mathrm{AD}$, cognitive deficits are not detectable until A $\beta$ deposits in the DG during stage 3 (Thal et al., 2000). Third, the DG may be more vulnerable to tau pathology because it contains less NFTresistant nitric oxide synthases (NOS) neurons relative to other regions of the hippocampus (Rebeck, Marzloff, \& Hyman, 1993).

The CA3 region may be of interest because hyperactivity in this region is observed in memory-impaired, aged rats (Wilson, Ikonen, Gallagher, Eichenbaum, \& Tanila, 2005), as well as MCI patients (Bakker et al., 2012; Yassa et al., 2010) and those at genetic risk for AD (Dennis et al., 2010; Filippini et al., 2009; Trivedi et al., 2008). This hyperactivity is partially due to a 
loss of inhibitory innervation from cholinergic cells in the basal forebrain (Chouinard, Gallagher, Yasuda, Wolfe, \& McKinney, 1995; Sugaya et al., 1998), which releases the CA3 recurrent, autoassociation fibers from inhibition, leading to greater activity (Leutgeb, Leutgeb, Treves, Moser, \& Moser, 2004). Similarly, loss of EC to DG innervation results in a loss of inhibitory input to CA3, resulting in increased CA3 activity (Bragin, Jando, Nadasdy, van Landeghem, \& Buzsaki, 1995).

Finally, the CA1 also exhibits tau pathology (Fukutani et al., 1995), and though the DG seems to be most sensitive to aging (Small, Chawla, Buonocore, Rapp, \& Barnes, 2004), the CA1 region shows a greater loss of neurons related to AD than any other region (West, Kawas, Martin, \& Troncoso, 2000). Thus, glutamate regulation in all three regions of the trisynaptic loop was examined.

To study glutamate dysregulation in the DG, CA3, and CA1, we employed a novel technique, in vivo amperometry coupled to enzyme-based microelectrode arrays (MEAs). Previous studies employing the use of microdialysis experienced spatial and temporal limitations that restricted the ability to sample dynamic changes in glutamate near the synapse (Hillered, Vespa, \& Hovda, 2005; Obrenovitch, Urenjak, Zilkha, \& Jay, 2000)). Damage caused by the large sample area (1-4 mm in length) limited the detection of neuronal release (Borland, Shi, Yang, \& Michael, 2005; Jaquins-Gerstl \& Michael, 2009), and the low temporal resolution (1-20 min) was inadequate to measure the fast dynamics of glutamate uptake and clearance (Diamond, 2005). MEAs allow for such measures due to their high temporal resolution $(10 \mathrm{~Hz})$, low limit of detection $(<0.5 \mu \mathrm{M})$, and high spatial resolution, to selectively measure extracellular glutamate close to synapses (Burmeister \& Gerhardt, 2001; Burmeister et al., 2002). Another benefit of MEAs over other ex vivo methods is the ability to study brain regions in vivo without disrupting 
their extrinsic and intrinsic connections, a particularly important consideration when examining the complex neural networks of the hippocampus. 


\section{Introduction}

Alzheimer's disease (AD) affects approximately 5.4 million Americans and is often characterized by progressive memory loss, decline in cognitive skills, and adverse behavioral changes (Thies \& Bleiler, 2013). Pathologically, AD is characterized by accumulation of neuritic $\mathrm{A} \beta$ plaques and abnormally phosphorylated tau leading to neurofibrillary tangles (Serrano-Pozo et al., 2011). The third major feature in $\mathrm{AD}$ is the alteration of neuronal connections, eventually leading to massive neuron loss throughout the brain. Neuropathology begins in the entorhinal cortex and then extends to the hippocampus, before spreading to the associated areas of the cortex (de Calignon et al., 2012; Liu et al., 2012; Nath et al., 2012).

Individuals at risk for developing $\mathrm{AD}$ often exhibit neuronal network hyperexcitability in the years preceding $\mathrm{AD}$ diagnosis, suggesting that aberrant network activity might contribute to the pathogenesis of $\mathrm{AD}$. In studies using functional magnetic resonance imaging (fMRI), elevated hippocampal activation is observed in individuals at risk for $\mathrm{AD}$, including cognitively normal carriers of the ApoE4 allele (Dennis et al., 2010; Filippini et al., 2009; Trivedi et al., 2008), pre-symptomatic carriers of genetic mutations in familial AD (Quiroz et al., 2010), patients with mild cognitive impairment (MCI) (Dickerson et al., 2005; Hamalainen et al., 2007), and asymptomatic and minimally impaired older individuals with amyloid deposition (Sperling et al., 2009). The CA3 region of the hippocampus is particularly prone to hyperexcitability (I. A. Wilson et al., 2005). Although, hippocampal activity was thought to be compensatory by recruiting extra neuronal resources (Bondi et al., 2005; Grady et al., 2003; Ward \& Frackowiak, 2003), more recent studies show excess activation may contribute directly to memory impairment and AD-related pathology and could represent a therapeutic target (Bakker et al., 2012). 
Recent work suggests tau may mediate hyperexcitability. Genetic removal of tau decreases seizure activity in an A $\beta$ mouse model of AD (Roberson et al., 2011). Furthermore, in this same mouse model, reducing endogenous tau ameliorated excitotoxicity and rescued cognitive dysfunction, without altering $A \beta$ levels (Roberson et al., 2007), suggesting tau, not $A \beta$, was mediating excitotoxicity. Deletion of tau in mouse and drosophila models of epilepsy also reduces hyperexcitability, as well as seizure frequency and duration (Daniels et al., 2011). The exact mechanism for these changes remains to be determined, but recent work suggests tau may alter glutamate neurotransmission (Roberson et al., 2007; Roberson et al., 2011; Timmer et al., 2014).

Glutamate, the major excitatory neurotransmitter is responsible for many of the brain's functions, including long-term potentiation (LTP), and learning and memory (Bliss \& Collingridge, 1993). Although beneficial at low levels, high concentrations of extracellular (EC) glutamate can lead to cell death through excessive activation of glutamate receptors, a process referred to as excitotoxicity (Olney et al., 1986). Excitotoxicity is linked to several neurodegenerative disorders, including AD (Hardingham \& Bading, 2010b), and occurs when uncontrolled glutamate release surpasses the capacity of astrocyte clearance mechanisms, leading to an excess of EC glutamate. Though many studies have implicated glutamate in the pathophysiology of $\mathrm{AD}$, most have done so through indirect measures, such as increased signaling of downstream pathways related to excitotoxicity (Hong et al., 2012; Saito et al., 1993; Zhang et al., 2010) or in cell culture models (Jamsa et al., 2006; Petroni et al., 2011). In vivo measurement of glutamate regulation in AD mouse models has been limited.

To determine the role of tau in glutamate dysregulation, the current study used TauP301L mice. These mice exhibit age-dependent tangles, cognitive decline, and neuron loss (Ramsden et 
al., 2005; Santacruz et al., 2005). However, we sought to examine the effects of P301L tau on glutamate dysregulation before neuron loss occurs (Hoover et al., 2010). TauWT animals were used to control for the overexpression of human tau. Prior to glutamate testing, mice were memory tested using the hippocampal-dependent Barnes maze (BM) task to ensure memory impairments at the age tested. In vivo glutamate dysregulation was measured in the DG, CA3, and CA1 subregions of the hippocampus, areas rich in glutamate receptors (Nimchinsky, Yasuda, Oertner, \& Svoboda, 2004; Pettit \& Augustine, 2000), using a technologically innovative technique, amperometry coupled to ceramic-based microelectrode arrays (MEAs). Unlike previous studies using microdialysis, MEAs selectively measure extracellular glutamate at $10 \mathrm{~Hz}$ enabling us to more precisely examine tonic glutamate levels, potassium chloride (KCl)-evoked glutamate release, and glutamate clearance (Burmeister \& Gerhardt, 2001; Burmeister et al., 2002). Another benefit of MEAs over other ex vivo methods is the ability to study brain regions in vivo without disrupting their extrinsic and intrinsic connections, a particularly important consideration when examining the complex connections of the hippocampus. Because all procedures were done within the same animal, we were able to relate changes in glutamatergic signaling with behavioral changes.

\section{Methods}

Subjects. Creation of TauP301L mice has been described extensively in the past (Hoover et al., 2010; Ramsden et al., 2005; Santacruz et al., 2005). Briefly, regulatable transgenic mice expressing human four-repeat tau lacking the N-terminal sequences $(4 \mathrm{R} 0 \mathrm{~N})$ with a P301L mutation were created by crossing a responder and activator line. Responder mice (FVB/N background strain) heterozygous for the TRE-TauP301L transgene were bred with heterozygous activator mice (129S6 background strain) that express the tet-off tetracycline transactivator (tTA) 
reading frame placed downstream of $\mathrm{Ca}^{2+} /$ calmodulin kinase II (CaMKII) promoter elements (Santacruz et al., 2005). The four genotypes of animals generated are described by the following nomenclature, TauP301L/CKtTA, and include what we refer to as TauP301L mice (+/+) and Controls $(-/+,+/-,-/-)$. In the current study we used the (-/+) control because no behavioral differences among the 3 Control groups has been reported, and human tau is not expressed in any of the Controls (Hoover et al., 2010; Ramsden et al., 2005; Santacruz et al., 2005), yet the -/+ allowed us to control for the expression of tTA (Mayford et al., 1996). TauWT were generated in the same way as TauP301L mice and have been shown to express wild-type 4R0N human tau at concentrations equivalent to P301L human tau in TauP301L mice (Hoover et al., 2010). To control for differences in copy number, which can affect transgene expression (Kong et al., 2009), mice were littermate-matched, and litter served as the statistical unit.

The CaMKII promoter was used to restrict TauP301L protein expression to the forebrain (Santacruz et al., 2005), which contains the brain regions most severely affected in AD (Auld, Kornecook, Bastianetto, \& Quirion, 2002), while the tet-off system allowed for regulatable expression of the tau protein. In the tet-off system, the tTA protein binds to TRE in the absence of doxycycline, allowing transcription and protein expression to occur (Liu, Wang, Brenner, Paton, \& Kasparov, 2008), whereas in the presence of doxycycline, the tTA protein cannot bind to TRE, allowing tau expression to be suppressed. To suppress tau expression during brain development, 40 ppm doxycycline hyclate (DOX) was administered (Figure 3) via water bottles to breeder dams for three weeks prior to mating and to all experimental mice from birth until 1.85 months \pm 1.5 weeks of age. Tau was expressed from two to seven months of age, with behavioral testing at 4.93 months \pm 1.28 weeks and glutamate testing at 7.01 months \pm 3.29 weeks. 
Twenty-eight mice (7 Controls, 12 TauWT, 9 TauP301L) of an FVB/129S6 background strain were group housed with free access to food and water in a temperature and humiditycontrolled colony room with a 12:12 light/dark cycle. Bodyweights did not differ among the groups (Figure 6A). All experimental procedures were approved by the West Virginia University Animal Care and Use Committee.

Barnes Maze. The Barnes maze consists of a circular white platform $(122 \mathrm{~cm}), 108 \mathrm{~cm}$ above the ground, with 40 holes $(5 \mathrm{~cm})$, one with a hidden escape box. Acquisition training was performed as described previously with slight modification (McAfoose, Koerner, \& Baune, 2009; McLay, Freeman, \& Zadina, 1998). For the two days preceding acquisition trials, the mice were habituated to the maze. The first day mice were placed under an opaque beaker, with lights on and allowed to enter the escape box for $5 \mathrm{~min}$. The next day the mouse was gently guided to the escape box and allowed to remain in the escape box for $2 \mathrm{~min}$. Each mouse completed two trials each day with approximately 20-25 min between trials.

For acquisition training, on days 3-7, mice were placed under a transparent, plastic beaker in the center of the platform, with lights on and four fans evenly placed around the maze. After $10 \mathrm{sec}$, the beaker was raised, and the mouse was free to find the escape box. The trials ended 30 sec after the mouse entered the escape box. If the mouse did not enter the escape box during the 3 min trial, the experimenter gently guided the mouse into the escape box and covered the hole for $30 \mathrm{sec}$. Mice received 3 trials per day with 20-25 min between trials. The maze was cleaned with $70 \%$ ethanol, rotated clockwise after every trial to avoid intra-maze odor or visual cues, though the escape box remained in the same place relative to extra-maze cues. Total acquisition errors were recorded. 
The first of two probe trials, in which the escape box was removed, took place $24 \mathrm{hr}$ after the last acquisition trial. The second probe trial took place one week following the first probe trial. Probe trials lasted $90 \mathrm{sec}$. Latency to reach the target hole and number of errors made were recorded. To further evaluate search strategy as previously described (Devan, Stouffer, Petri, McDonald, \& Olds, 2003), the probe trial was divided into three $30 \mathrm{sec}$ epochs.

Enzyme-based microelectrode arrays. Ceramic-based MEAs were used to examine glutamate dysregulation and were purchased from Quanteon, L.L.C. (Nicholasville, KY). The array consisted of a ceramic-based multisite microelectrode with 4 platinum recording sites (Burmeister \& Gerhardt, 2001) (Figure 4A). These sites were arranged in dual pairs to allow interfering agents to be detected and removed from the analyte signal (Burmeister \& Gerhardt, 2001). Coating of the microelectrodes has been described previously (Hinzman et al., 2010). Briefly, the recording sites were covered with glutamate-oxidase (GluOx) to oxidize glutamate to alpha-ketoglutarate and hydrogen peroxide $\left(\mathrm{H}_{2} \mathrm{O}_{2}\right)$, the reporter molecule (Burmeister \& Gerhardt, 2001). An inactive protein matrix covered the other pair of recording sites (sentinel sites). Small molecules, like $\mathrm{H}_{2} \mathrm{O}_{2}$, could diffuse through the mPD exclusion layer and were detected by both the sentinel and reporter sites. The background current from the sentinel sites was then subtracted from the recording sites to produce a selective measure of extracellular glutamate. A reference electrode $\mathrm{Ag} / \mathrm{AgCl}$ was implanted into a remote site from the recording area so as to decrease noise and instability (Burmeister \& Gerhardt, 2001).

Calibration. Calibrations were conducted on the MEAs to ensure specificity prior to use in mice and to create a standard curve for the conversion of current to glutamate concentration (Figure 4B). Using the FAST-16 mkII system (Quanteon), a constant potential of $+0.7 \mathrm{~V}$ versus an $\mathrm{Ag} / \mathrm{AgCl}$ reference was applied to the MEA to oxidize the reporter molecule. The resulting 
current was amplified by the FAST 16 mkII system. The MEA tip was submerged in $40 \mathrm{~mL}$ of a $0.05 \mathrm{M}$ phosphate-buffered saline (PBS) maintained at $37^{\circ} \mathrm{C}$. A standard curve was produced by adding successive aliquots of $20 \mu \mathrm{L}$ glutamate to achieve concentrations of 20,40 , and $60 \mu \mathrm{M}$. The increase in current (nA) produced by oxidation was used to calculate the calibration slope to a known concentration of glutamate (Burmeister, et al., 2002). To determine selectivity for glutamate, ascorbic acid $(250 \mu \mathrm{M})$, dopamine $(2 \mu \mathrm{M})$, and $8.8 \mathrm{H}_{2} \mathrm{O}_{2}(8.8 \mu \mathrm{M})$ was added to solution (Hinzman, Thomas, Quintero, Gerhardt, \& Lifshitz, 2012). To determine the limit of detection, the smallest concentration of glutamate that can be measured by the device, the slope of the standard curve was used, as well as the linearity of glutamate response $\left(\mathrm{R}^{2}\right)$ (Hinzman et al., 2012). We also examined MEA performance after in vivo recordings. As previously reported, post-implantation calibration demonstrated that the parameters were not different when compared to pre-implantation (Hinzman et al., 2010). Both GluOX recording sites (pre- vs. postimplantation), reported as means ( $\mathrm{n}=1$ electrode): limit of detection $(.54 \mu \mathrm{M}$ vs. $2.26 \mu \mathrm{M}), \mathrm{R}-$ squared (.99 vs. .99), and slope (.002 pA/ $\mu \mathrm{M}$ vs. .002 pA/ $\mu \mathrm{M})$.

MEA/Micropipette Assembly. For intracranial drug deliveries, a glass micropipette with an inner diameter tip of $10-15 \mu \mathrm{m}$ (Quanteon) was attached to the MEA. The micropipette was centered between the dorsal and ventral platinum recording pairs and positioned $80-100 \mu \mathrm{m}$ away from the MEA. Location of the micropipette to the MEA was verified post-surgery to ensure the pipette did not move. The micropipette was back-filled with sterile-filtered isotonic $\mathrm{KCl}$ solution $\left(70 \mathrm{mM} \mathrm{KCl}, 79 \mathrm{mM} \mathrm{NaCl}, 2.5 \mathrm{mM} \mathrm{CaCl}_{2}, \mathrm{pH} 7.4\right)$ or glutamate solution $(200 \mu \mathrm{M}$ glutamate, $\mathrm{pH}$ 7.4). The micropipette was attached to a Picospritzer III (Parker-Hannifin, Cleveland, $\mathrm{OH}$ ) and set to consistently deliver volumes of 50-100 nL. Pressure was applied from 
2 - 20 psi for .30-2.5 sec. Volume displacement was monitored with the use of a stereomicroscope fitted with a reticule (Friedemann \& Gerhardt, 1992).

In vivo Anesthetized Recording. Mice were anesthetized with isoflurane (1-4\% inhalation; continuous) and placed into a stereotaxic device (David Kopf Instruments, Tujunga, CA, USA). Isoflurane was used because other anesthesias have been shown to alter resting glutamate levels (Mattinson et al., 2011). Though initial reports suggested isoflurane increases tau phosphorylation (Planel et al., 2004), more recent reports suggest that when anesthesiainduced hypothermia is controlled for, isoflurane does not increase tau phosphorylation (Tan et al., 2010). To ensure our mice did not become hypothermic while under anesthesia, body temperature was maintained at $37^{\circ} \mathrm{C}$ with a water pad connected to a recirculating water bath (Gaymar Industries Inc., Orchard Park, NY).

A craniotomy was performed to allow access to the hippocampus. The reference electrode was placed under the skin with a saline-soaked gauze pad in the hemisphere opposite from the recording sites. The MEA/micropipette targeted the DG, CA3, and CA1 of the hippocampus, all subregions known to be rich in glutamate receptors (Nimchinsky et al., 2004; Pettit \& Augustine, 2000). Stereotaxic coordinates for the different subregions of the hippocampus were calculated using the mouse brain atlas (Paxinos \& Watson 2004) [DG (AP: $2.3 \mathrm{~mm}, \mathrm{ML}:+/-1.5 \mathrm{~mm}, \mathrm{DV}: 2.1 \mathrm{~mm}$ ), CA3 (AP: $-2.3 \mathrm{~mm}, \mathrm{ML}:+/-2.7 \mathrm{~mm}, \mathrm{DV}: 2.25 \mathrm{~mm}$ ), CA1 (AP: $-2.3 \mathrm{~mm}, \mathrm{ML}:+/-1.7 \mathrm{~mm}, \mathrm{DV}: 1.4 \mathrm{~mm}$ )] and confirmed in practice mice prior to MEA testing. All MEA recordings were performed at $10 \mathrm{~Hz}$ using constant potential amperometry. After the MEA reached a stable baseline (10-20 min), tonic glutamate levels $(\mu \mathrm{M})$ were calculated averaging extracellular glutamate levels over 10 seconds prior to any application of solutions. In all three subregions of one hemisphere, evoked release was measured by local 
application of $\mathrm{KCl}$ delivered every 2-3 minutes. After 10 reproducible signals, the results were averaged for each group. Each signal was analyzed using (1) amplitude $(\mu \mathrm{M})$, maximum glutamate release, (2) $\mathrm{T}_{\text {rise, }}$, time for the signal to reach maximum amplitude, (3) $\mathrm{T}_{80}(\mathrm{sec})$, time for the signal to decay $80 \%$ from the peak amplitude, and (4) uptake $\mathrm{k}_{-1}\left(\mathrm{sec}^{-1}\right)$, the slope of linear regression of the natural log transformation of the decay over time (Figure 5) (Hinzman et al., 2010; Hinzman et al., 2012; Nickell, Salvatore, Pomerleau, Apparsundaram, \& Gerhardt, 2007). KCl-evoked release of glutamate was measured to determine the capacity or "ceiling" of the terminal to release glutamate (Hinzman et al., 2010).

To control for differences in extracellular glutamate levels, thereby allowing a clean interpretation of clearance parameters, exogenous glutamate was applied in the opposite hemisphere. After the MEA reached a stable baseline (10-20 min), varying volumes of $200 \mu \mathrm{M}$ sterile-filtered glutamate solution were applied into the extracellular space every 2-3 minutes. Glutamate signals with amplitudes in the $0-40 \mu \mathrm{M}$ range were analyzed as this was the physiological range of $\mathrm{KCl}$-evoked glutamate release observed in the current study. Amplitudes were matched across the groups and glutamate clearance $\left(\mathrm{T}_{80}\right.$ and $\left.\mathrm{k}_{-1}\right)$ was measured.The hemispheres used for $\mathrm{KCl}$ and glutamate application were counterbalanced as was the order of subregions within a hemisphere.

Statistical analyses. All statistical analyses were performed using Systat11 (Systat Software, Inc., Chicago 60606). Statistical analysis consisted of ANOVA and repeated-measures ANOVA (RMANOVA). The Type I error rate (So was set at .05 for all omnibus tests and Bonferroni post hoc comparisons. For the RMANOVA of behavioral data, transgene status served as the between-subject variable, and session served as the within-subject variable. Amperometric data were analyzed using a custom Microsoft excel software program (MatLab) to 
determine the tonic levels and $\mathrm{KCl}$-evoked signal parameters. To determine concentrations of glutamate in the hippocampus, the background current from the sentinel sites was subtracted from the signal obtained from the GluOx recording sites. The resting current (pA) was divided by the slope $(\mu \mathrm{M} / \mathrm{pA})$ obtained during calibration and reported as a concentration of tonic glutamate. Using Pearson $\mathrm{r}$ correlations, we correlated $\mathrm{KCl}$-evoked release in the CA3 with errors made during the 24-hour probe trial of the Barnes maze.

\section{Results}

Barnes maze: spatial learning and memory. TauP301L mice made more errors across acquisition training days (days 3-7) than the Controls [Tg main effect: $F(2,25)=4.32, p=.03$ ] (Figure 5B); errors between the groups did not differ across acquisition [Tg*Day interaction: $F(8,100)=1.64, p=.12]$. Latency did not differ among the groups during acquisition [Tg main effect: $F(2,25)=1.45, p=.25$; Tg*Day interaction: $F(8,100)=1.39, p=.21]$. For the 24 hour probe trial, TauP301L mice more errors than Controls and TauWT mice, with a marginal effect $[F(2,23)=3.13, p=.06)]$ (Figure 5C). To determine whether mice extinguished preference for the target hole where the escape box had been located across the $90 \mathrm{sec}$ probe trial (Devan et al., 2003), probe trial errors were binned into three $30 \mathrm{sec}$ epochs. TauP301L mice made significantly more errors than Controls and TauWT mice in the middle, 30-60 sec epoch $[F(2,23)$ $=3.98, p=.03)]($ Figure 5D). For the 1 week probe trial, there were no differences among the groups for total errors, errors in the three epochs, or latency $(p>.05)$.

In vivo microelectrode recordings: tonic and evoked glutamate release. Tonic glutamate levels were not significantly different in the DG $[F(2,17)=.15 ; p=.86]$, CA3 $[F(2,16)$ $=.11 ; p=.89]$, or CA1 $[F(2,17)=.58 ; p=.57]$ among the Controls, TauWT, or TauP301L mice (Figure 7A). Local application of $50-100 \mathrm{~nL}$ of $70 \mathrm{mM} \mathrm{KCl}$ produced reproducible glutamate 
release in all regions of the hippocampus. Though resting levels did not differ among the groups, $\mathrm{KCl}$-evoked glutamate release was significantly increased in TauP301L mice (Figure 7B). The amplitudes of KCL-evoked-glutamate release in the dentate gyrus and CA1 were similar among the groups, whereas in the $\mathrm{CA} 3$, the amplitude of $\mathrm{KCl}$-evoked glutamate release was 7 times larger in the TauP301L mice [Tg main effect; $F(2,17)=4.33, p=.03$ ]. Also, a significantly longer $\mathrm{T}_{80}$, time for the signal to decay by $80 \%$ from the peak amplitude, was observed following KCl-evoked glutamate release in DG of TauP301L mice $[F(2,18)=3.68, p=.04$; Table 1$]$. Clearance parameters $\left(\mathrm{T}_{80}\right.$ and $\left.\mathrm{K}_{-1}\right)$ were equivalent for all hippocampal regions across the groups (Table 1).

$\mathrm{KCl}$-evoked glutamate release in the CA3 was positively correlated with total probe errors $[r(19)=.501, p=.03]$ and probe errors in the first and last $30 \mathrm{~s}$ epochs $[0-30 \mathrm{~s}: r(19)=$ $.479 p=.04 ; 60-90 \mathrm{~s}: r(19)=.452, p=.05$, when all mice were included (Figure 8). When examined by group (Table 2), the correlation was not statistically significant for TauWT or TauP301L, but was surprisingly strong for Controls with $\mathrm{r}$ values reaching as high as 0.942 .

In vivo microelectrode recordings: clearance parameters. Rapid application of glutamate into the extracellular space allowed us to mimic endogenous glutamate release and examine glutamate clearance back to baseline in vivo. Since the amplitude of glutamate signals were similar among Controls, TauWT, and TauP301L mice in the DG $[F(2,12)=.76 ; p=.49]$, CA3 $[F(2,13)=.52 ; p=.60]$, and CA1 $[F(2,15)=.09 ; p=.91]$, we compared specific parameters of glutamate clearance (Figure 9A). We calculated $\mathrm{T}_{\text {rise, }}$, the time for signal to reach maximum amplitude, to examine if transgene altered diffusion of glutamate in the extracellular space. Because $\mathrm{T}_{\text {rise }}$ was not significantly different among the groups DG $[F(2,15)=2.25 ; p=$ $.15], \mathrm{CA} 3[F(2,13)=.51 ; p=.61]$, and CA1 $[F(2,15)=.31 ; p=.74]$, any reductions in glutamate 
clearance were not due to diffusion from the point source (micropipette) to the MEA (Sykova, Mazel, \& Simonova, 1998)(Figure 9B). $\mathrm{T}_{80}$, time for the signal to decay to $80 \%$ from peak amplitude, in the DG $[F(2,12)=.33 ; p=.73], \mathrm{CA} 3[F(2,13)=1.16 ; p=.34]$, and CA1 $[F(2,15)$ $=.24 ; p=.79]$ and $\mathrm{K}_{-1}$, a measure of glutamate uptake, in the DG $[F(2,12)=.35 ; p=.71]$, CA3 $[F(2,13)=.33 ; p=.73]$, and CA1 $[F(2,15)=2.37 ; p=.13]$ were not significantly different among Controls, TauWT, or TauP301L mice (Figure 9C-9D).

\section{Discussion}

We examined the extent of glutamate dysregulation in a TauP301L mouse model of AD known to exhibit electrophysiological hyperexcitability prior to tangle deposition or neuronal death (Crimins et al., 2012). The present study was the first to use in vivo amperometry to examine glutamate dysregulation in the DG, CA3, and CA1 subregions of the hippocampus in an AD mouse model. The hippocampal-dependent Barnes maze task was used to relate pathological glutamate changes with functional deficits. TauP301L mice exhibited memory deficits with greater total errors across acquisition days and probe trial errors. Though tonic glutamate levels were unaltered in all three regions of the hippocampus, $\mathrm{KCl}$-evoked glutamate release in the CA3 was significantly increased in TauP301L mice. Glutamate clearance and uptake did not differ among the groups.

The Barnes maze is a spatial memory task that requires animals to use spatial cues around the room to learn the position of a hole that can be used to escape the brightly lit, aversive, open surface of the maze. Rodents with hippocampal damage show impaired performance in the Barnes maze, suggesting this is a hippocampal-dependent task (Fox, Fan, LeVasseur, \& Faden, 1998; Pompl, Mullan, Bjugstad, \& Arendash, 1999). Unlike the commonly used hippocampaldependent Morris water maze, the Barnes maze task does not require the mice to swim and is 
therefore considered less anxiogenic (Harrison, Hosseini, \& McDonald, 2009), a notion

supported by findings of lower plasma corticosterone in rodents examined after the Barnes maze compared to the Morris water maze task (Harrison et al., 2009). Because stress is related to both an increase in extracellular glutamate (Popoli et al., 2012) and an increase in tau hyperphosphorylation (Popoli et al., 2012; Sotiropoulos et al., 2011), the Barnes maze task was identified as a more suitable measurement of memory for the current study. The present findings confirm that the Barnes maze is a sensitive task for use with TauP301L mice, capable of detecting subtle differences after a short duration of tau expression.

The tonic glutamate levels observed in the current study (1-3 uM) were similar to the levels previously reported in the hippocampus of microdialysis studies using rats (1-4 uM) (Herman \& Jahr, 2007; Lerma, Herranz, Herreras, Abraira, \& Martin del Rio, 1986; Miele, Berners, Boutelle, Kusakabe, \& Fillenz, 1996). Interestingly, in vitro studies using hippocampal brain slices suggest much lower ambient glutamate concentrations, with values closer to 0.025 $\mu \mathrm{M}$ (Herman \& Jahr, 2007). The reason for these discrepancies between in vitro and in vivo studies is unclear and warrants further investigation.

P301L tau expression did not alter tonic glutamate levels. The lack of differences in tonic glutamate for TauP301L mice is somewhat surprising given the increased VGLUT expression and $\mathrm{KCl}$-evoked release observed in these mice. However, in vitro studies using hippocampal slices suggest tonic glutamate levels are not dependent on, or altered by, vesicular release but may instead be due to differences in glia-dependent release of glutamate (Cavelier \& Attwell, 2005; Jabaudon et al., 1999; Le Meur, Galante, Angulo, \& Audinat, 2007). In vivo studies using MEAs provide indirect support for this idea. In mice with traumatic brain injury, striatal tonic levels were increased, yet KCl-evoked released remained unchanged (Hinzman et al., 2010). 
MEA research with aging rats shows that the opposite is also possible; aged rats exhibited increased KCl-evoked release, but unaltered levels of tonic glutamate (Stephens, Quintero, Pomerleau, Huettl, \& Gerhardt, 2011), similar to the present findings. Future studies are needed to further delineate and confirm glia as primary sources of tonic extracellular glutamate.

TauP301L mice exhibit increases in KCL-evoked glutamate release in all regions of the hippocampus, but this increase was only significant in the CA3 region. The increased release of CA3 glutamate in TauP301L suggests that the CA3 hyperactivity observed in MCI patients performing memory tasks (Bakker et al., 2012) could be due to an increase in glutamate release, though further work is needed to confirm this hypothesis. We also observed that evoked release in the CA3 was positively correlated with errors in the BM task during the 24 hour probe trial, suggesting that memory may be mediated in part by increases in glutamate release. Human evidence also supports this view; in memory-impaired aged humans, poorer memory performance correlates with CA3 hyperexcitability (Bragin et al., 1995). This relation is more than correlation; reductions in CA3 activity improve memory in aged rats (Koh et al., 2010) and MCI patients (Bakker et al., 2012). Similarly, increased hippocampal activation in MCI is predictive of the degree and rate of cognitive decline, as well as the conversion to AD (Mackenzie \& Miller, 1994).

Recent work sheds light on one possible way in which hyperactivity might be permissive for the development of $\mathrm{AD}$. In $\mathrm{AD}$, tau - typically an intracellular protein - is released into the extracellular space and endocytosed by neighboring neurons (Liu et al., 2012). This spread occurs along synaptically connected circuits, resulting in a prion-like cell-to-cell transmission of tau pathology. Relevant to the current paper is the finding that presynaptic glutamate release is sufficient to drive tau release into the extracellular space (Yamada et al., 2014). Thus, glutamate- 
mediated exocytosis of tau may indicate one mechanism for the trans-synaptic spread of tau pathology associated with synaptic activity. This could also result in a vicious feed-forward cycle whereby tau pathology increases glutamate release, which then propagates the spread of tau pathology. Further studies are needed to establish the relevance of increased CA3 glutamate release to the spread of tau pathology.

The increased $\mathrm{KCl}$-evoked release observed in TauP301L mice could arise through several different mechanisms. For example, the increased expression of VGLUT observed in TauP301L mice could explain the increase in glutamate release. The number of VGLUT molecules has a direct impact on the number of glutamate molecules released by a single synaptic vesicle during exocytosis (Herzog, Takamori, Jahn, Brose, \& Wojcik, 2006; N. R. Wilson et al., 2005) and overexpression of VGLUT results in increased glutamate release, leading to excitotoxic neurodegeneration and a shortened lifespan (Daniels et al., 2011). The increase in $\mathrm{KCl}$-evoked release could also be explained by a reduction in glutamate transporter expression, resulting in slower clearance of evoked glutamate from the synapse. That is, it is possible increased levels observed after local application of $\mathrm{KCl}$ are not due to increased release but rather less clearance, leading to overall higher levels. However, when exogenous glutamate was applied, no differences in clearance were observed in TauP301L mice.

In many neurodegenerative diseases, including amyotrophic lateral sclerosis (ALS) (Rothstein, Van Kammen, Levey, Martin, \& Kuncl, 1995), Huntington's disease (Arzberger, Krampfl, Leimgruber, \& Weindl, 1997), Parkinson's disease (Ferrarese et al., 1999), and Alzheimer's disease (Masliah et al., 2000), astrocytic glutamate transporter expression is decreased. However, because brains are often examined at the end-stage of these diseases, neuronal loss is often extensive, making it difficult to discern the role of glutamate transporters 
in the pathogenesis of these diseases. To better examine the role of glutamate transporters in the etiology of $\mathrm{AD}$, mouse models have been examined. In JNPL-c tau transgenic mice, which also express the P301L mutation in tau but throughout the brain, glutamate transporter (GLT-1) expression is increased by about 25\% (Liao et al., 2009). Interestingly, this increase in GLT-1 expression is associated with decreased damage following stroke-induced excitotoxicity (Liao et al., 2009). Whether the increase in GLT-1 expression associated with P301L tau is a neuroprotective or compensatory response for increased glutamate release is unclear. Evidence that increase in GLT-1 expression might be a compensatory response for alterations in glutamate release comes from MEA studies examining aged rats. In the DG of older rats, glutamate uptake is increased (Stephens et al., 2011). This age-associated increase in glutamate uptake coincides with an increase in glutamate release, suggesting a possible compensatory response.

There is also evidence for a compensatory increase in glutamate transporters in human brain tissue. Compared to age-matched controls, examination of post-mortem AD brain tissue showed increased EAAT1 expression in neurons, as opposed to astrocytes, the more typical location of EAAT1 (Scott et al., 2002). Tau was colocalized to the same pyramidal neurons that expressed EAAT1, suggesting that neuronal transporter changes may also be related to tau pathology. Similarly, EAAT2, typically found on astrocytes in healthy tissue, are also found in neurons in AD post-mortem brain tissue (Thai, 2002). It is tempting to propose that neuronal expression of EAAT1 and EAAT2 represents a neuroprotective response to combat excitotoxicity. It will be important that future studies measure transporter expression in concordance with the microelectrode studies and distinguish between neuronal versus astrocytic transporter expression. 
One potential caveat of the current study concerns the high spatial resolution of the microelectrodes. Because of the high spatial resolution, it is possible that different coordinates within the various subregions of the hippocampus would result in different effects than those observed here. In fact, when examined using MEAs, tonic glutamate levels were increased in rat with traumatic brain injury but only at certain depths within the striatum (Hinzman et al., 2010); increases in tonic glutamate levels were observed at a depth of $4.0 \mathrm{~mm}$, but not at $4.5 \mathrm{~mm}$ or 5.0 mm. Thus, examination of TauP301L mice using slightly different coordinates might reveal different results. Though the spatial resolution can be a limitation, it is also a benefit, allowing subregional analyses and measurements of fast transmission close to the synapse.

In conclusion we used MEAs in combination with TauP301L mice to examine the effects of P301L tau expression on glutamate signaling, without other mediators, such as $\mathrm{A} \beta$ plaques, tangles, and neuronal loss. Our results demonstrate memory-impaired TauP301L mice exhibit a 7-fold increase in KCL-evoked glutamate release in the CA3 region of the hippocampus. The more research is needed to determine the specific mechanisms responsible for elevations in glutamate release and the potential implications for the spread of tau pathology.

Limitations. Although mice were anesthetized, and anesthesia often alters resting glutamate levels (Mattinson et al., 2011) and tau phosphorylation (Planel et al., 2004), mice were anesthetized with isoflurane, which does not alter glutamate levels or tau (Tan et al., 2010). A second potential caveat of the current study concerns the high spatial resolution of the microelectrodes. Because of the high spatial resolution, it is possible that different coordinates within the various subregions of the hippocampus would result in different effects than those observed here. Thus, examination of TauP301L mice using slightly different coordinates might 
reveal different results. It should also be noted that although we examined glutamate dysregulation, we did not directly measure hyperexcitability using electrophysiology. 
Table 1

Clearance Parameters of KCl-Evoked Glutamate Release

\begin{tabular}{lllllll}
\hline & \multicolumn{3}{c}{$\mathbf{T}_{\mathbf{8 0}}(\mathbf{s e c})$} & & \multicolumn{3}{c}{$\mathbf{K}_{\mathbf{- 1}}\left(\mathbf{s e c}^{-1}\right)$} \\
& Controls & TauWT & TauP301L & Controls & TauWT & TauP301L \\
\cline { 2 - 7 } DG & $1.74 \pm .54$ & $2.19 \pm .61$ & $8.56 \pm 3.34 *$ & $2.69 \pm 1.73$ & $1.67 \pm 1.01$ & $2.83 \pm 1.31$ \\
CA3 & $3.77 \pm 1.23$ & $4.01 \pm .77$ & $5.13 \pm 1.53$ & $4.61 \pm 1.96$ & $.64 \pm 1.13$ & $2.82 \pm 1.75$ \\
CA1 & $2.27 \pm .69$ & $4.83 \pm 2.41$ & $3.71 \pm 1.03$ & $3.36 \pm .57$ & $1.02 \pm .73$ & $2.10 \pm 1.36$ \\
\hline
\end{tabular}

Mean \pm SEM; DG $n=7$; CA3 $n=7$; CA1 $n=7 .{ }^{*} p<.05$, ANOVA, Control vs. TauP301L. 
Table 2. Correlations between $\mathrm{KCl}$-evoked glutamate release in the $\mathrm{CA} 3$ and errors in the 24 hour probe trial of the Barnes maze.

\begin{tabular}{|c|c|c|c|}
\hline & Controls & TauWT & TauP301L \\
\hline $\begin{array}{l}\text { Total } \\
\text { Probe } \\
\text { Errors }\end{array}$ & $\begin{array}{c}27.65+16.95 * \text { KCl-Glut } \\
r(6)=.909, p=.012\end{array}$ & $\begin{array}{c}93.66+.63 * \mathrm{KCl}-\mathrm{Glut} \\
r(7)=.153, p=.744\end{array}$ & $\begin{array}{c}96.67+.73 * \mathrm{KCl}-\mathrm{Glut} \\
r(6)=.55, p=.257\end{array}$ \\
\hline $\begin{array}{l}\text { Epoch 1: } \\
\text { 0-30 s }\end{array}$ & $\begin{array}{c}6.31+5.97 * \text { KCl-Glut } \\
r(6)=.942, p=.006\end{array}$ & $\begin{array}{c}27.28+.37 * \mathrm{KCl}-\mathrm{Glut} \\
r(7)=.231, p=.618\end{array}$ & $\begin{array}{c}23.95+.387 * \mathrm{KCl}-\mathrm{Glut} \\
r(6)=.527, p=.283\end{array}$ \\
\hline $\begin{array}{l}\text { Epoch 2: } \\
30-60 \mathrm{~s}\end{array}$ & $\begin{array}{c}8.34+6.08 * \text { KCl-Glut } \\
r(6)=.929, p=.007\end{array}$ & $\begin{array}{c}39.22-.56 * \mathrm{KCl} \text {-Glut } \\
r(7)=.319, p=.486\end{array}$ & $\begin{array}{c}8.38 .41+.19 * \text { KCl-Glut } \\
r(6)=.365, p=.483\end{array}$ \\
\hline $\begin{array}{c}\text { Epoch 3: } \\
60-90 \mathrm{~s}\end{array}$ & $\begin{array}{c}13.01+4.89 * \mathrm{KCl}-\mathrm{Glut} \\
r(6)=.755, p=.083\end{array}$ & $\begin{array}{c}27.15+.82 * \mathrm{KCl}-\mathrm{Glut} \\
r(7)=.476, p=.279\end{array}$ & $\begin{array}{c}34.30+.16 * \mathrm{KCl}-\mathrm{Glut} \\
r(6)=.431, p=.394\end{array}$ \\
\hline
\end{tabular}

$\mathrm{KCl}$-evoked glutamate levels in the CA3 were positively correlated with total errors in the 24 hour probe trial, epoch1, and epoch 2 in control mice, but were not significant in TauWT or TauP301L. $(p<.05, \mathrm{n}=6-7)$; potassium chloride $(\mathrm{KCl})$, glutamate (Glut). 

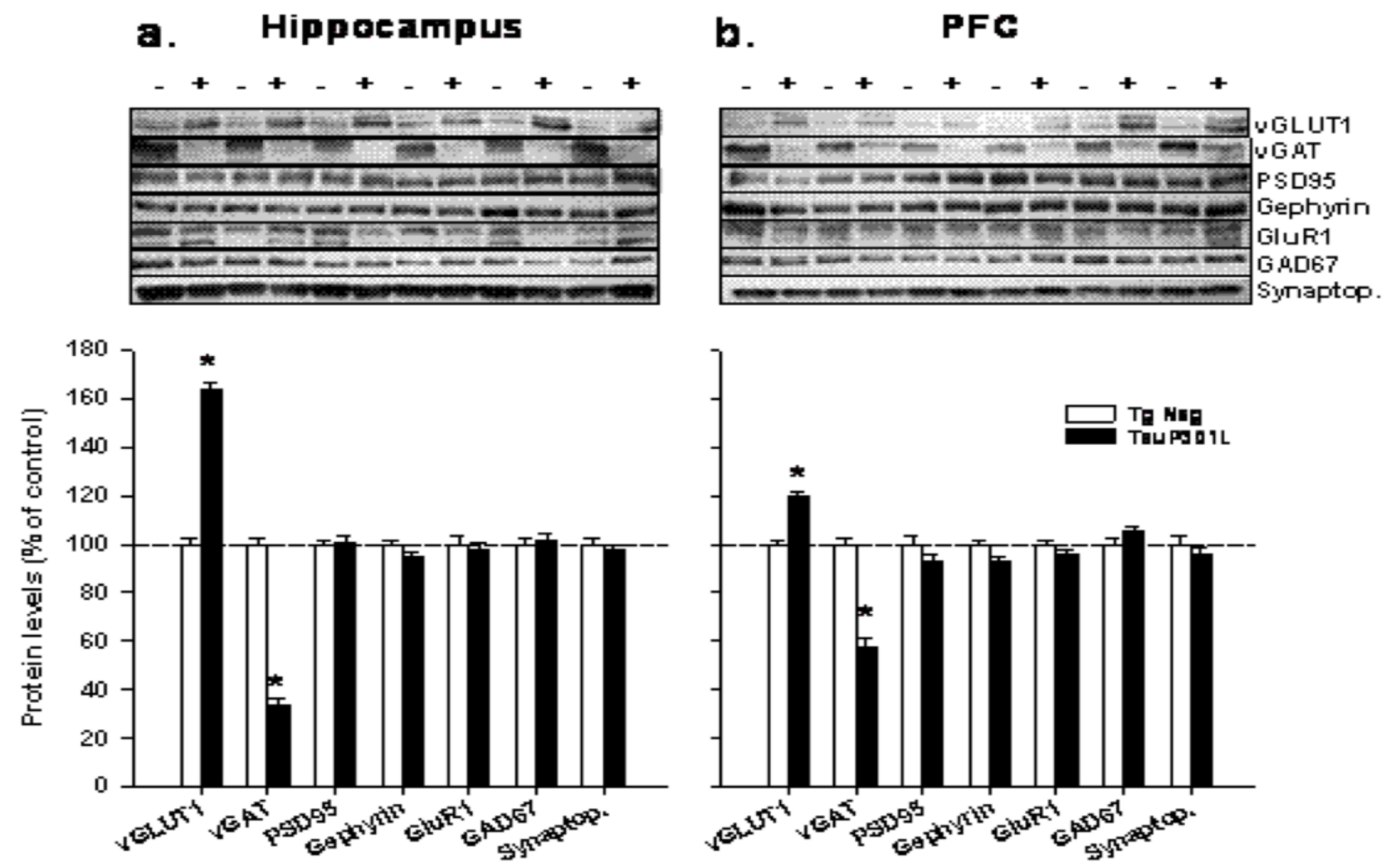

Figure 1.TauP301L mice (+) exhibit a 65\% increase in VGLUT1 expression in the hippocampus and a $20 \%$ increase in the prefrontal cortex (PFC) compared to controls (-). Synaptophysin, a marker of presynaptic terminals, and PSD95, a postsynaptic marker, did not differ between the groups, indicating TauP301L mice do not exhibit synapse loss at the time point examined. VGAT, the vesicular transporter for GABA, an inhibitory neurotransmitter, was decreased by $70 \%$ in the hippocampus and $40 \%$ in the PFC. Increased VGLUT and decreased VGAT are predicted to produce excitotoxicity. Means \pm SEM. $\left(n=12\right.$ per group). ${ }^{*} p<0.01$. Vesciular glutamate transporter 1 (VGLUT1); vesicular GABA transporter (VGAT); Post synaptic density protein 95 (PSD95); $\alpha$-hydroxy-5-methyl-4-isoxazolepropionic acid glutamate receptor 1 (GluR1); Glutamic acid decarboxylase 67 (GAD67); Synaptophysin (Synaptop.) (Data not published). 


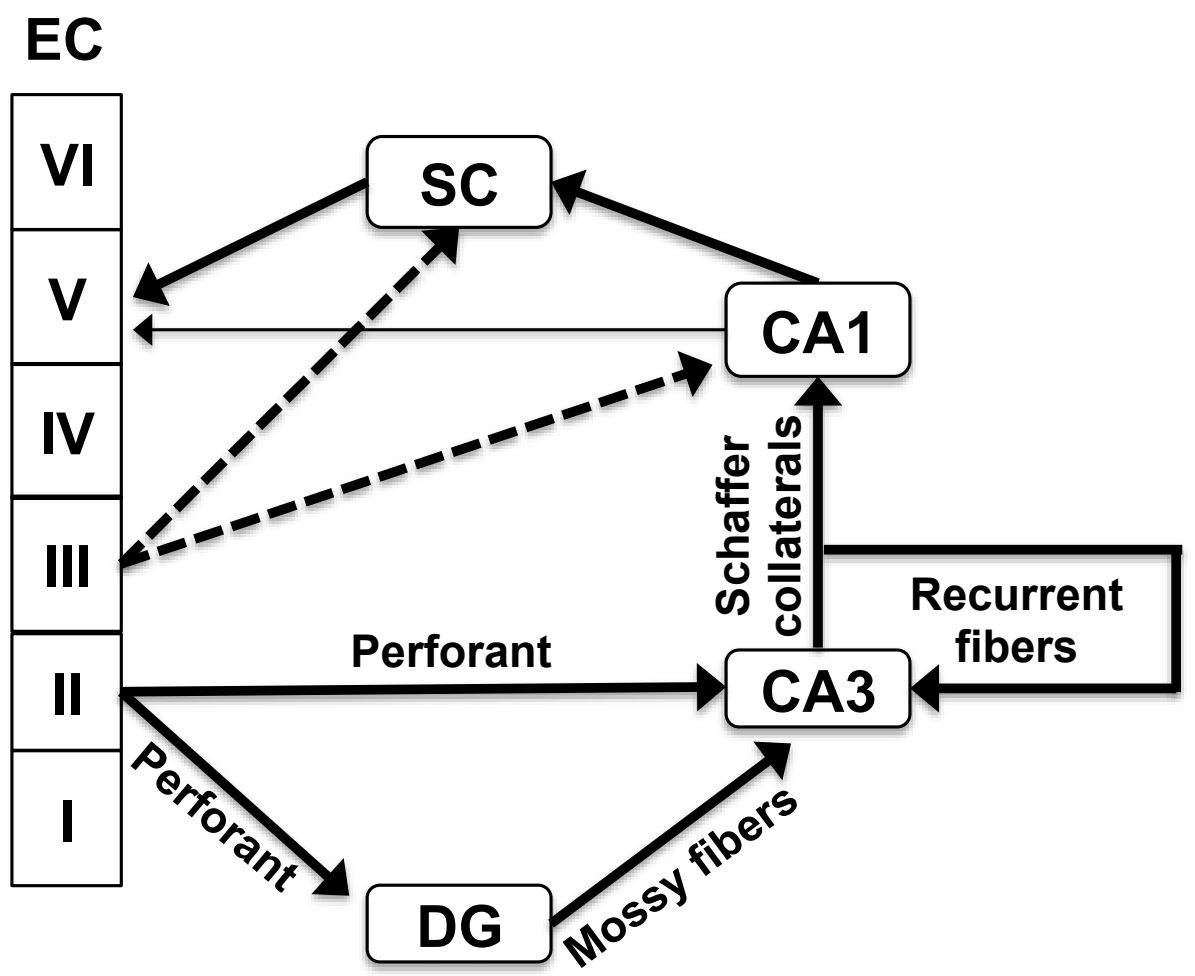

Figure 2. The trisynaptic circuit of the hippocampus. Information enters this unidirectional loop through layer II of the entorhinal cortex (EC). The EC transmits signals along the perforant pathway via axons and connects to the dentate gyrus (DG). The mossy fibres of the DG then synapse onto pyramidal cells in the CA3, which connect to the CA1 region via the Schaffer collaterals. From the CA1, projections lead to the subiculum (SC), where the SC, and to a lesser extent the CA1, project to the EC again, forming the third link of the circuit. In addition, to the unidirectional flow, layer III of the EC directly connects to the CA1 and SC (dotted lines), and layer II of the EC provides direct connections to the CA3 via the perforant pathway. CA3 neurons also receive more than $95 \%$ of their input from recurrent CA3 collaterals, referred to as "auto-associative" tracts. 


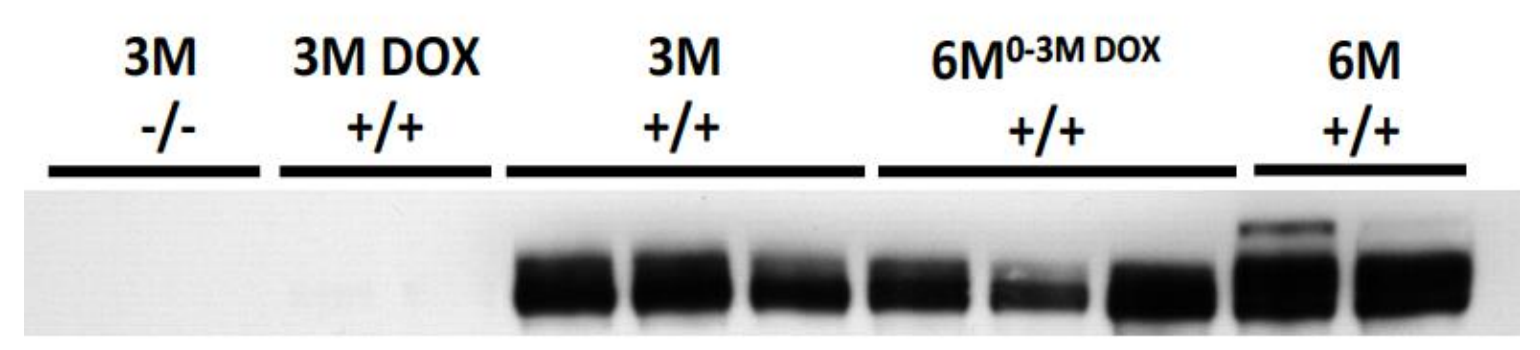

Figure 3. Suppression of tau. Using an antibody that recognizes human tau (Tau-13), the ability of doxycycline (DOX) to suppress tau expression. DOX treatment in TauP301L mice (3M DOX $+/+$ ) suppresses tau expression. Six month old mice on DOX from 0-3 months but allowed to express tau from 3-6 months (6M (0-3M DOX)) express tau at approximately equal levels as TauP301L mice expressing tau for 3 and 6 months without DOX treatment $(3 \mathrm{M}+/+$ and $6 \mathrm{M}$ +/+). Tau negative mice, -/-; TauP301L mice, +/+. 
A.

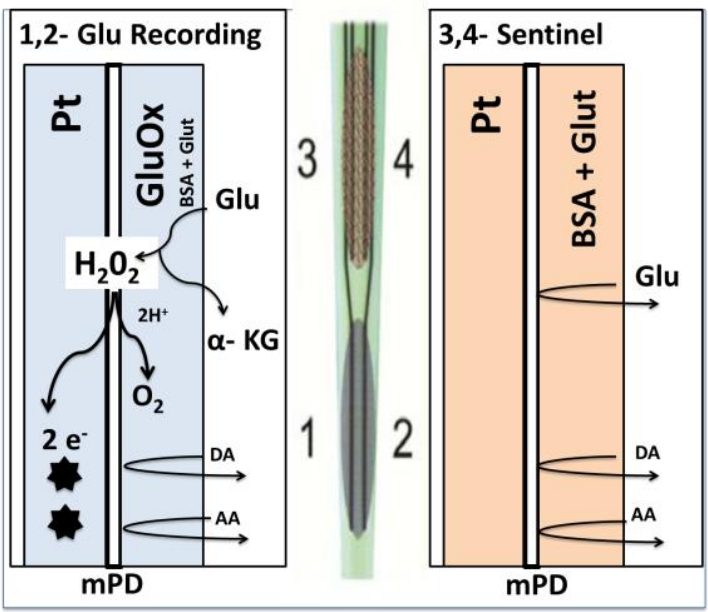

B.

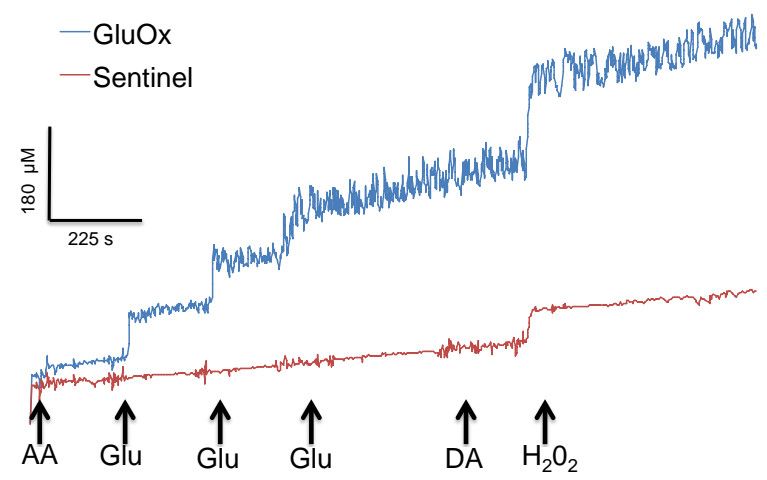

Figure 4. Microelectrode graphics. (A) Schematic drawing showing the configuration and coatings applied to the MEA. The lower pair of platinum sites were prepared with a mixture of glutamate-oxidase (GluOX), bovine serum albumin (BSA), and glutaraldehyde (Glut), illustrated at left. The upper pair of platinum sites were prepared only with BSA and Glut, illustrated at right. A layer of $\mathrm{m}$-phenylenediamine (mPD) is electroplated onto the recording sites providing a size exclusion layer to block major interferents, ascorbic acid (AA) and dopamine (DA). (B) MEA in vitro calibration measuring the change in the GluOx site (blue line) and sentinel site (red line) using multiple additions of glutamate (Glu). Addition of interferents (AA and DA) produced no changes in concentration on the GluOx or sentinel sites. Three additions of glutamate produced changes in concentration on the GluOx sites only while $\mathrm{H}_{2} \mathrm{O}_{2}$ produced changes on both the GluOx and sentinel sites. 


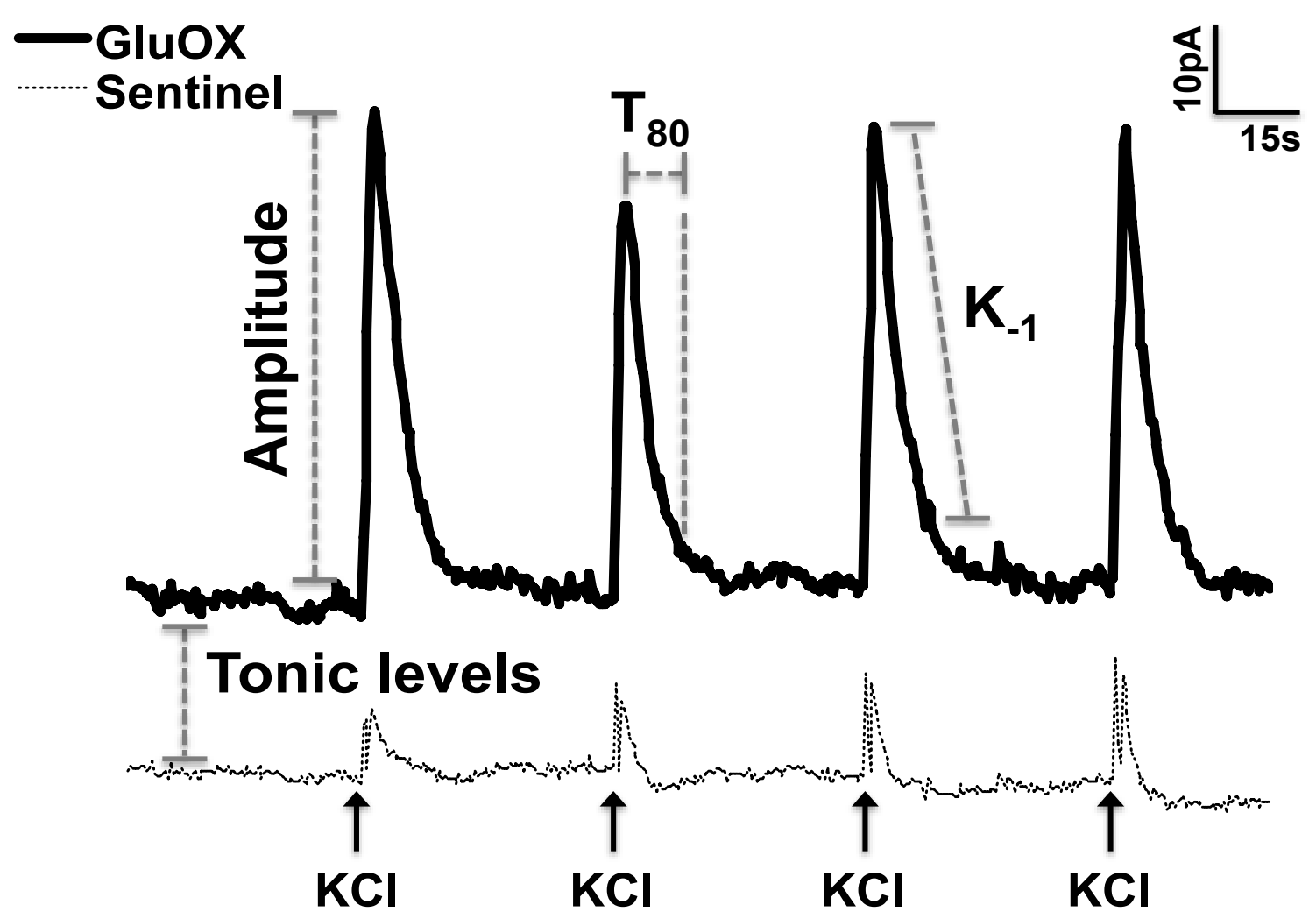

Figure 5. Illustrative in vivo recording from the GluOX sites (solid line) and sentinel sites (dashed line). To measure resting (tonic) glutamate, current from the sentinel sites were subtracted from the glutamate oxidase $(\mathrm{GluOX})$ sites. Potassium chloride $(\mathrm{KCl})$ was used to examine the maximum amplitude of evoked glutamate release. Exogenous glutamate was applied to measure clearance of glutamate from the synapse. $\mathrm{T}_{80}$, the time for the peak to decay to $80 \%$ and $\mathrm{k}_{-1}$, the clearance rate, were used as clearance parameters. 

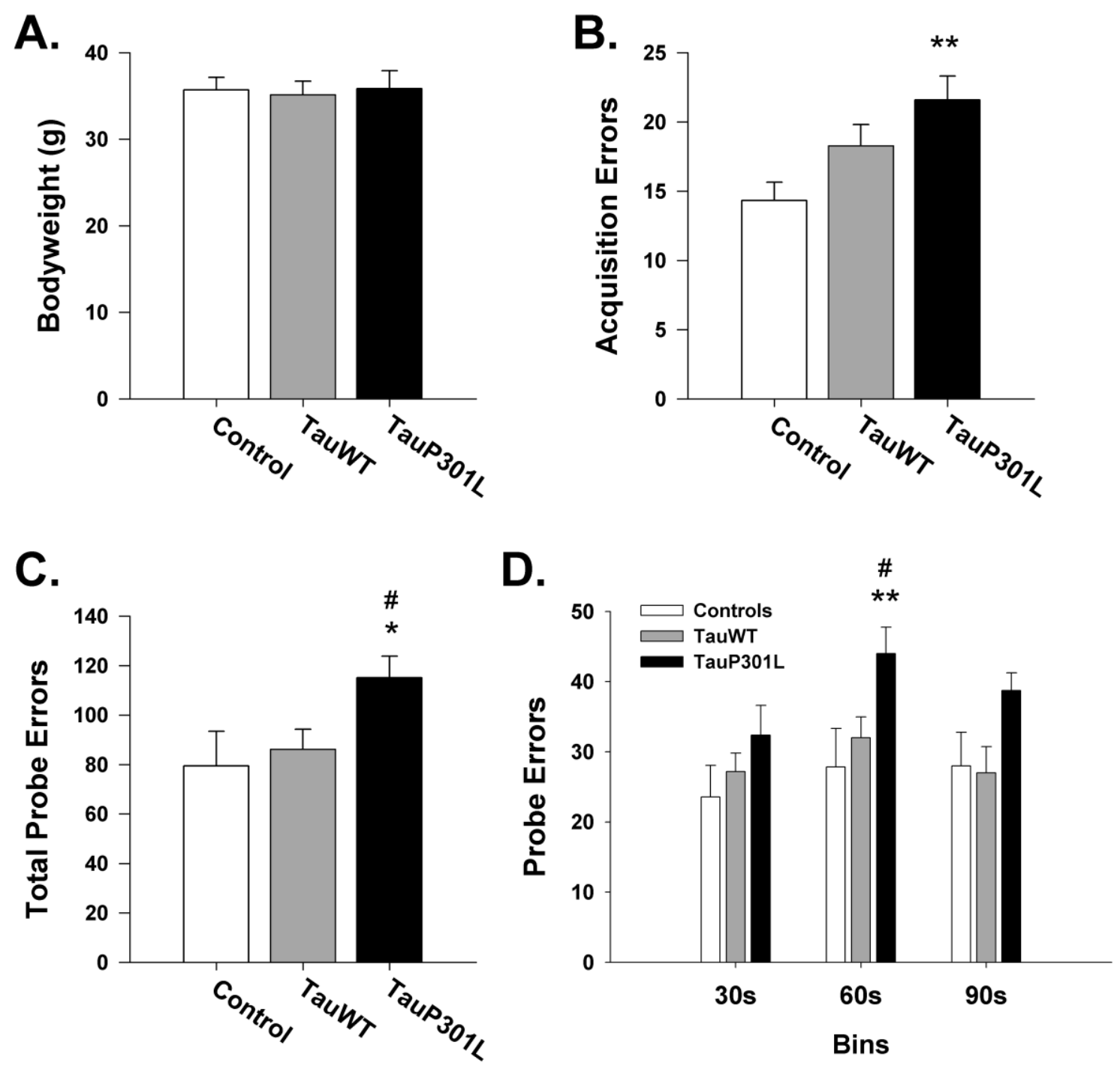

Figure 6. TauP301L mice exhibit memory deficits in the Barnes maze task. (A) Bodyweights were not significantly different. (B) Errors during acquisition were significantly increased for TauP301L mice. (C) TauP301L mice exhibited more errors during probe trials. (D) TauP301L mice made more errors during the 30-60 sec epoch. (Mean \pm SEM; * $p<.05$ Control vs. TauP301L, $* * p<.01$ Control vs. TauP301L, \# $p<.05$ TauWT vs. TauP301L, $n=7-11)$. 

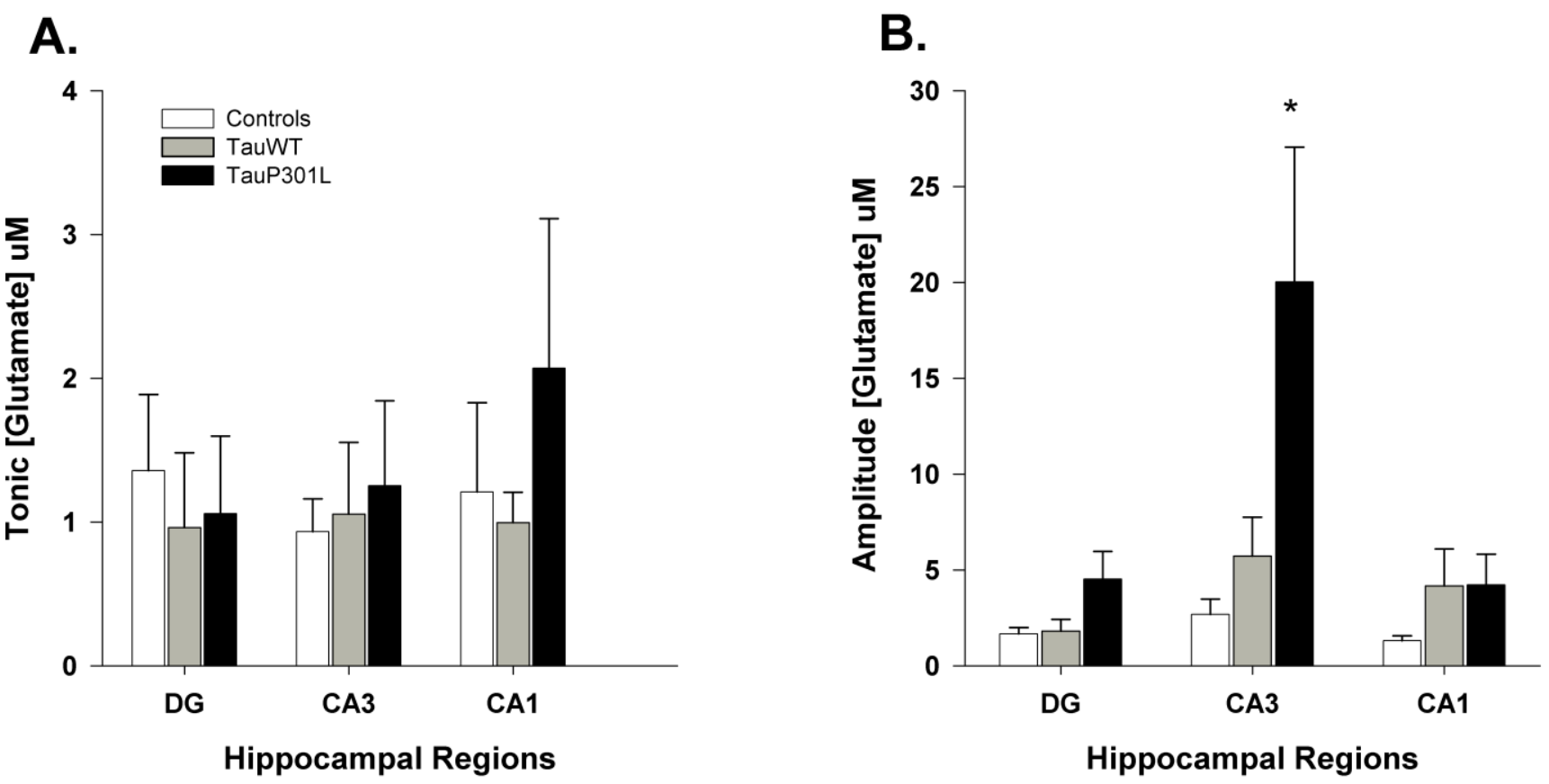

Figure 7. Tonic and potassium chloride $(\mathrm{KCl})$-evoked release of glutamate in the $\mathrm{DG}, \mathrm{CA} 3$, and CA1 regions of the hippocampus. (A) Tonic glutamate levels were not significantly different in the hippocampus. (B) The average amplitudes of $\mathrm{KCl}$-evoked glutamate release in the CA3 region of hippocampus were significantly increased in the TauP301L mice after local application of 50-100 nL of $70 \mathrm{mM} \mathrm{KCl}$, compared to Controls or TauWT animals (Mean $\pm \mathrm{SEM} ;{ }^{*} p<.05$ Control vs. TauP301L, $n=6-7)$. 

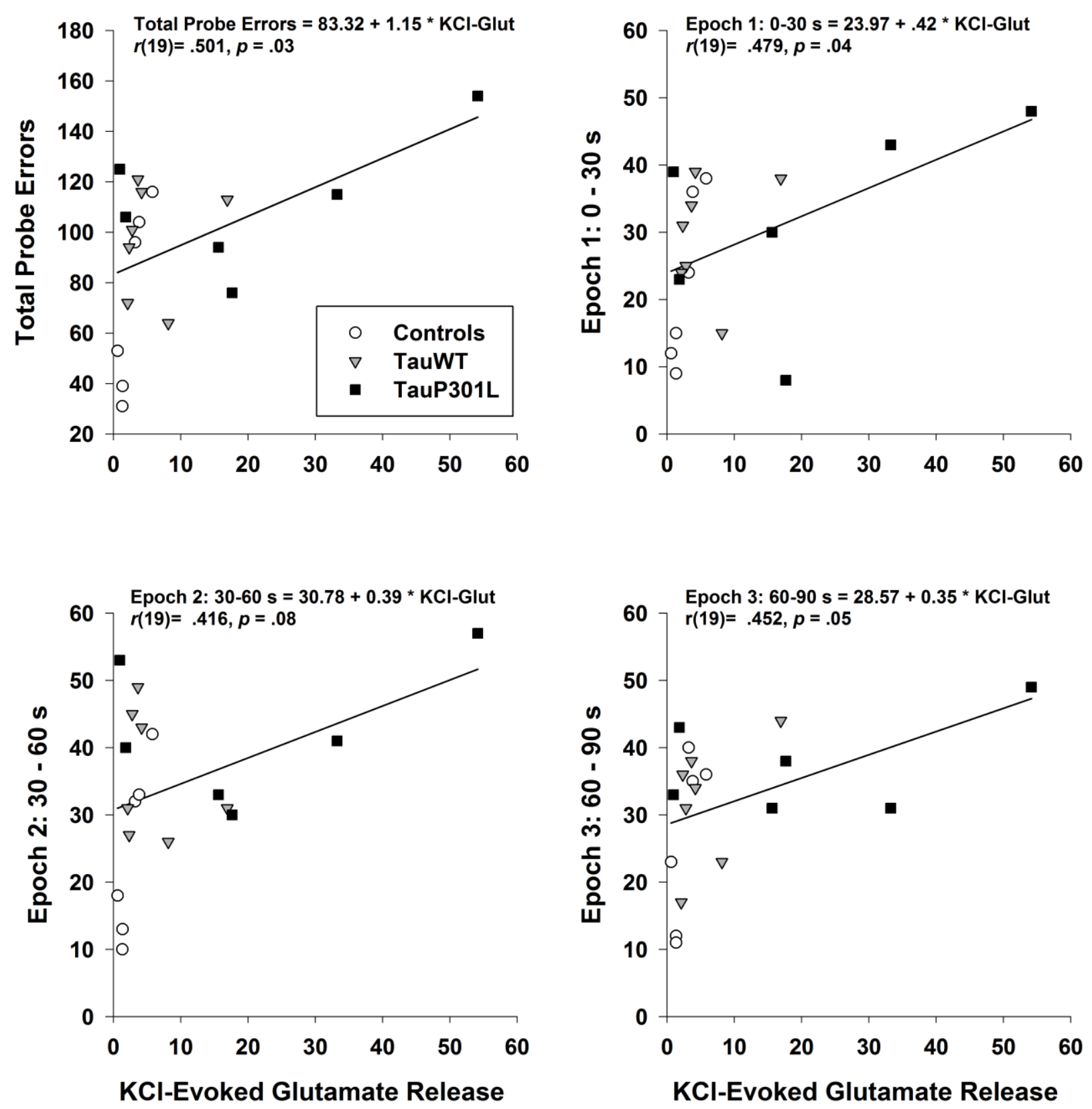

Figure 8. Correlations of CA3 $\mathrm{KCl}$-evoked glutamate release. $\mathrm{KCl}$-evoked glutamate release in the CA3 was positively correlated with (A) total errors in the 24 hour probe trial, (B) Epoch 1: 030 s, (C) Epoch 2: 30-60 s, and (D) Epoch 3: 60-90 s. Potassium chloride, KCl; glutamate, Glu. 


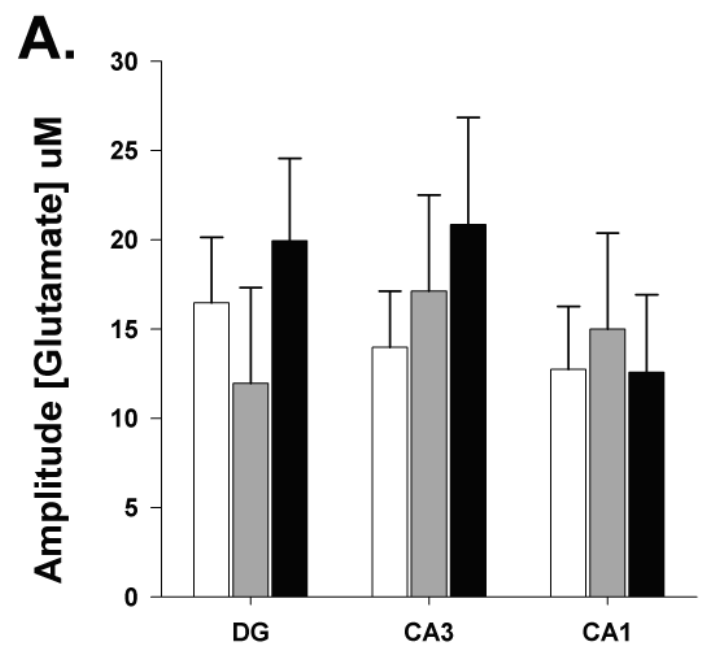

Hippocampal Regions

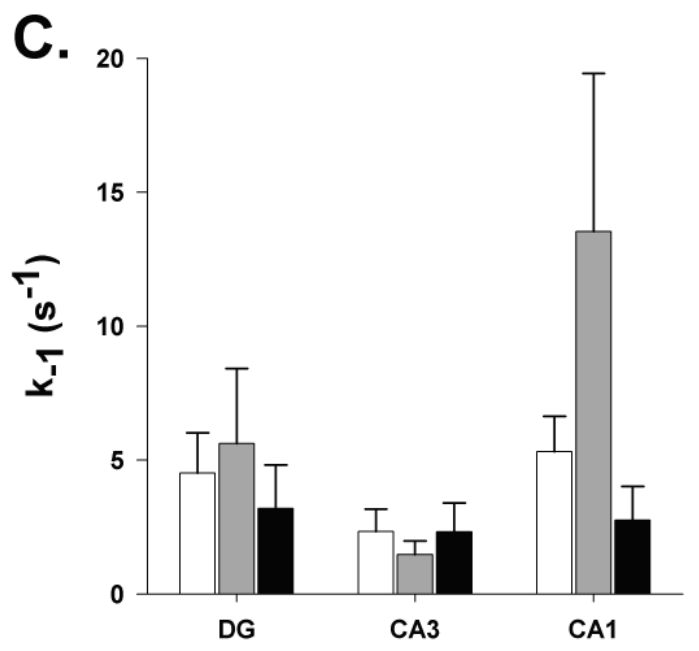

Hippocampal Regions

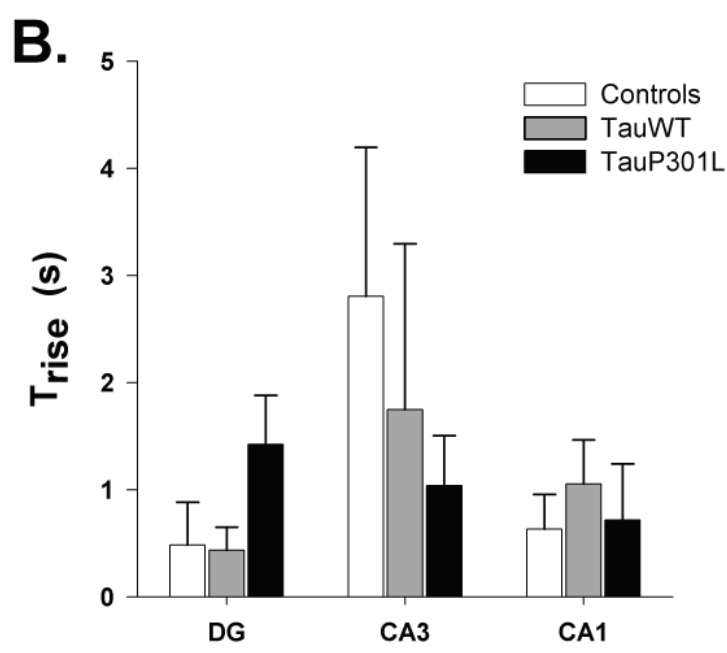

Hippocampal Regions

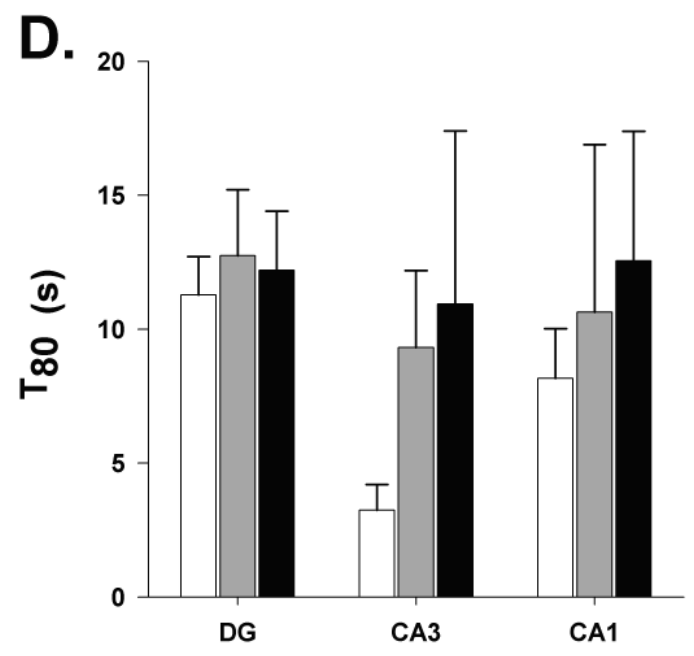

Hippocampal Regions

Figure 9. Clearance parameters in the DG, CA3, and, CA1 using exogenous glutamate. (A)

When glutamate was applied, the amplitude of glutamate signal was similar among groups in each region. (B) $\mathrm{T}_{\text {rise, }}$ indicator of diffusion, was similar among groups in each region. (C) $\mathrm{K}_{-1}$, indicator of glutamate uptake, did not differ among groups in each region. (D) $\mathrm{T}_{80}$, indicator or glutamate clearance, did not differ among groups in each region. 


\section{References}

Al-Hallaq, R. A., Jarabek, B. R., Fu, Z., Vicini, S., Wolfe, B. B., \& Yasuda, R. P. (2002). Association of NR3A with the N-methyl-D-aspartate receptor NR1 and NR2 subunits. Mol Pharmacol, 62(5), 1119-1127.

Aleppo, G., Pisani, A., Copani, A., Bruno, V., Aronica, E., D'Agata, V., . . Nicoletti, F. (1992). Metabotropic glutamate receptors and neuronal toxicity. Adv Exp Med Biol, 318, 137145.

Allyson, J., Dontigny, E., Auberson, Y., Cyr, M., \& Massicotte, G. (2010). Blockade of NR2Acontaining NMDA receptors induces Tau phosphorylation in rat hippocampal slices. Neural Plast, 2010, 340168. doi: 10.1155/2010/340168

Amadoro, G., Ciotti, M. T., Costanzi, M., Cestari, V., Calissano, P., \& Canu, N. (2006). NMDA receptor mediates tau-induced neurotoxicity by calpain and ERK/MAPK activation. Proc Natl Acad Sci U S A, 103(8), 2892-2897. doi: 10.1073/pnas.0511065103

Annunziato, L., Cataldi, M., Pignataro, G., Secondo, A., \& Molinaro, P. (2007). Glutamateindependent calcium toxicity: introduction. Stroke, 38(2 Suppl), 661-664. doi: 10.1161/01.str.0000247942.42349.37

Anson, L. C., Chen, P. E., Wyllie, D. J., Colquhoun, D., \& Schoepfer, R. (1998). Identification of amino acid residues of the NR2A subunit that control glutamate potency in recombinant NR1/NR2A NMDA receptors. J Neurosci, 18(2), 581-589.

Aronica, E., Gorter, J. A., Ijlst-Keizers, H., Rozemuller, A. J., Yankaya, B., Leenstra, S., \& Troost, D. (2003). Expression and functional role of mGluR3 and mGluR5 in human 
astrocytes and glioma cells: opposite regulation of glutamate transporter proteins. Eur $J$ Neurosci, 17(10), 2106-2118.

Arriza, J. L., Eliasof, S., Kavanaugh, M. P., \& Amara, S. G. (1997). Excitatory amino acid transporter 5, a retinal glutamate transporter coupled to a chloride conductance. Proc Natl Acad Sci U S A, 94(8), 4155-4160.

Arzberger, T., Krampfl, K., Leimgruber, S., \& Weindl, A. (1997). Changes of NMDA receptor subunit (NR1, NR2B) and glutamate transporter (GLT1) mRNA expression in Huntington's disease--an in situ hybridization study. J Neuropathol Exp Neurol, 56(4), 440-454.

Auld, D. S., Kornecook, T. J., Bastianetto, S., \& Quirion, R. (2002). Alzheimer's disease and the basal forebrain cholinergic system: relations to beta-amyloid peptides, cognition, and treatment strategies. Prog Neurobiol, 68(3), 209-245.

Baker, D. A., Xi, Z. X., Shen, H., Swanson, C. J., \& Kalivas, P. W. (2002). The origin and neuronal function of in vivo nonsynaptic glutamate. J Neurosci, 22(20), 9134-9141.

Bakker, A., Krauss, G. L., Albert, M. S., Speck, C. L., Jones, L. R., Stark, C. E., . . Gallagher, M. (2012). Reduction of hippocampal hyperactivity improves cognition in amnestic mild cognitive impairment. Neuron, 74(3), 467-474. doi: 10.1016/j.neuron.2012.03.023

Bannai, S. (1986). Exchange of cystine and glutamate across plasma membrane of human fibroblasts. J Biol Chem, 261(5), 2256-2263.

Beckstrom, H., Julsrud, L., Haugeto, O., Dewar, D., Graham, D. I., Lehre, K. P., . . Danbolt, N. C. (1999). Interindividual differences in the levels of the glutamate transporters GLAST 
and GLT, but no clear correlation with Alzheimer's disease. J Neurosci Res, 55(2), 218229.

Behrens, M. M., Strasser, U., Heidinger, V., Lobner, D., Yu, S. P., McDonald, J. W., ... Choi, D. W. (1999). Selective activation of group II mGluRs with LY354740 does not prevent neuronal excitotoxicity. Neuropharmacology, 38(10), 1621-1630.

Benarroch, E. E. (2010). Glutamate transporters: diversity, function, and involvement in neurologic disease. Neurology, 74(3), 259-264. doi: 10.1212/WNL.0b013e3181cc89e3

Bettler, B., Boulter, J., Hermans-Borgmeyer, I., O'Shea-Greenfield, A., Deneris, E. S., Moll, C., . . Heinemann, S. (1990). Cloning of a novel glutamate receptor subunit, GluR5: expression in the nervous system during development. Neuron, 5(5), 583-595.

Bettler, B., Egebjerg, J., Sharma, G., Pecht, G., Hermans-Borgmeyer, I., Moll, C., . . . Heinemann, S. (1992). Cloning of a putative glutamate receptor: a low affinity kainatebinding subunit. Neuron, 8(2), 257-265.

Bezzi, P., Gundersen, V., Galbete, J. L., Seifert, G., Steinhauser, C., Pilati, E., \& Volterra, A. (2004). Astrocytes contain a vesicular compartment that is competent for regulated exocytosis of glutamate. Nat Neurosci, 7(6), 613-620. doi: 10.1038/nn1246

Bliss, T. V., \& Collingridge, G. L. (1993). A synaptic model of memory: long-term potentiation in the hippocampus. Nature, 361(6407), 31-39. doi: 10.1038/361031a0

Bliss, T. V., \& Gardner-Medwin, A. R. (1973). Long-lasting potentiation of synaptic transmission in the dentate area of the unanaestetized rabbit following stimulation of the perforant path. $J$ Physiol, 232(2), 357-374. 
Bliss, T. V., \& Lomo, T. (1973). Long-lasting potentiation of synaptic transmission in the dentate area of the anaesthetized rabbit following stimulation of the perforant path. $J$ Physiol, 232(2), 331-356.

Bollmann, J. H., Sakmann, B., \& Borst, J. G. (2000). Calcium sensitivity of glutamate release in a calyx-type terminal. Science, 289(5481), 953-957.

Bondi, M. W., Houston, W. S., Eyler, L. T., \& Brown, G. G. (2005). fMRI evidence of compensatory mechanisms in older adults at genetic risk for Alzheimer disease. Neurology, 64(3), 501-508. doi: 10.1212/01.wnl.0000150885.00929.7e

Bookheimer, S. Y., Strojwas, M. H., Cohen, M. S., Saunders, A. M., Pericak-Vance, M. A., Mazziotta, J. C., \& Small, G. W. (2000). Patterns of brain activation in people at risk for Alzheimer's disease. N Engl J Med, 343(7), 450-456. doi: 10.1056/nejm200008173430701

Borland, L. M., Shi, G., Yang, H., \& Michael, A. C. (2005). Voltammetric study of extracellular dopamine near microdialysis probes acutely implanted in the striatum of the anesthetized rat. J Neurosci Methods, 146(2), 149-158. doi: 10.1016/j.jneumeth.2005.02.002

Boulland, J. L., Osen, K. K., Levy, L. M., Danbolt, N. C., Edwards, R. H., Storm-Mathisen, J., \& Chaudhry, F. A. (2002). Cell-specific expression of the glutamine transporter SN1 suggests differences in dependence on the glutamine cycle. Eur J Neurosci, 15(10), 16151631.

Braak, H., \& Braak, E. (1998). Argyrophilic grain disease: frequency of occurrence in different age categories and neuropathological diagnostic criteria. J Neural Transm, 105(8-9), 801819. 
Bragin, A., Jando, G., Nadasdy, Z., van Landeghem, M., \& Buzsaki, G. (1995). Dentate EEG spikes and associated interneuronal population bursts in the hippocampal hilar region of the rat. Journal of Neurophysiology, 73(4), 1691-1705.

Brightwell, J. J., Gallagher, M., \& Colombo, P. J. (2004). Hippocampal CREB1 but not CREB2 is decreased in aged rats with spatial memory impairments. Neurobiol Learn Mem, 81(1), $19-26$.

Bruno, V., Copani, A., Knopfel, T., Kuhn, R., Casabona, G., Dell'Albani, P., . . Nicoletti, F. (1995). Activation of metabotropic glutamate receptors coupled to inositol phospholipid hydrolysis amplifies NMDA-induced neuronal degeneration in cultured cortical cells. Neuropharmacology, 34(8), 1089-1098.

Burbaeva, GSh, Boksha, I. S., Turishcheva, M. S., Vorobyeva, E. A., Savushkina, O. K., \& Tereshkina, E. B. (2003). Glutamine synthetase and glutamate dehydrogenase in the prefrontal cortex of patients with schizophrenia. Prog Neuropsychopharmacol Biol Psychiatry, 27(4), 675-680.

Burmeister, J. J., \& Gerhardt, G. A. (2001). Self-referencing ceramic-based multisite microelectrodes for the detection and elimination of interferences from the measurement of L-glutamate and other analytes. Anal Chem, 73(5), 1037-1042.

Burmeister, J. J., Pomerleau, F., Palmer, M., Day, B. K., Huettl, P., \& Gerhardt, G. A. (2002). Improved ceramic-based multisite microelectrode for rapid measurements of L-glutamate in the CNS. J Neurosci Methods, 119(2), 163-171.

Burnashev, N., Khodorova, A., Jonas, P., Helm, P. J., Wisden, W., Monyer, H., . . Sakmann, B. (1992). Calcium-permeable AMPA-kainate receptors in fusiform cerebellar glial cells. Science, 256(5063), 1566-1570. 
Cao, X., Cui, Z., Feng, R., Tang, Y. P., Qin, Z., Mei, B., \& Tsien, J. Z. (2007). Maintenance of superior learning and memory function in NR2B transgenic mice during ageing. Eur $J$ Neurosci, 25(6), 1815-1822. doi: 10.1111/j.1460-9568.2007.05431.x

Cavelier, P., \& Attwell, D. (2005). Tonic release of glutamate by a DIDS-sensitive mechanism in rat hippocampal slices. J Physiol, 564(Pt 2), 397-410. doi: 10.1113/jphysiol.2004.082131

Charpak, S., Gahwiler, B. H., Do, K. Q., \& Knopfel, T. (1990). Potassium conductances in hippocampal neurons blocked by excitatory amino-acid transmitters. Nature, 347(6295), 765-767. doi: 10.1038/347765a0

Chittajallu, R., Vignes, M., Dev, K. K., Barnes, J. M., Collingridge, G. L., \& Henley, J. M. (1996). Regulation of glutamate release by presynaptic kainate receptors in the hippocampus. Nature, 379(6560), 78-81. doi: 10.1038/379078a0

Choi, D. W. (1987). Ionic dependence of glutamate neurotoxicity. J Neurosci, 7(2), 369-379.

Choi, D. W. (1992). Excitotoxic cell death. J Neurobiol, 23(9), 1261-1276. doi: 10.1002/neu.480230915

Choi, D. W., Koh, J. Y., \& Peters, S. (1988). Pharmacology of glutamate neurotoxicity in cortical cell culture: attenuation by NMDA antagonists. $J$ Neurosci, 8(1), 185-196.

Choi, D. W., Maulucci-Gedde, M., \& Kriegstein, A. R. (1987). Glutamate neurotoxicity in cortical cell culture. J Neurosci, 7(2), 357-368.

Chouinard, Michael L., Gallagher, Michela, Yasuda, Robert P., Wolfe, Barry B., \& McKinney, Michael. (1995). Hippocampal muscarinic receptor function in spatial learning-impaired aged rats. Neurobiol Aging, 16(6), 955-963. doi: http://dx.doi.org/10.1016/01974580(95)02015-2 
Crimins, J. L., Rocher, A. B., \& Luebke, J. I. (2012). Electrophysiological changes precede morphological changes to frontal cortical pyramidal neurons in the rTg4510 mouse model of progressive tauopathy. Acta Neuropathol, 124(6), 777-795. doi: $10.1007 / \mathrm{s} 00401-012-1038-9$

Crino, P. B., Jin, H., Shumate, M. D., Robinson, M. B., Coulter, D. A., \& Brooks-Kayal, A. R. (2002). Increased expression of the neuronal glutamate transporter (EAAT3/EAAC1) in hippocampal and neocortical epilepsy. Epilepsia, 43(3), 211-218.

Curtis, D. R., Phillis, J. W., \& Watkins, J. C. (1960). The chemical excitation of spinal neurones by certain acidic amino acids. J Physiol, 150, 656-682.

Danbolt, N. C. (2001). Glutamate uptake. Prog Neurobiol, 65(1), 1-105.

Daniels, R. W., Miller, B. R., \& DiAntonio, A. (2011). Increased vesicular glutamate transporter expression causes excitotoxic neurodegeneration. Neurobiol Dis, 41(2), 415-420. doi: 10.1016/j.nbd.2010.10.009

de Calignon, A., Polydoro, M., Suarez-Calvet, M., William, C., Adamowicz, D. H., Kopeikina, K. J., . . . Hyman, B. T. (2012). Propagation of tau pathology in a model of early Alzheimer's disease. Neuron, 73(4), 685-697. doi: 10.1016/j.neuron.2011.11.033

Deisseroth, K., Bito, H., \& Tsien, R. W. (1996). Signaling from synapse to nucleus: postsynaptic CREB phosphorylation during multiple forms of hippocampal synaptic plasticity. Neuron, 16(1), 89-101.

Dennis, N. A., Browndyke, J. N., Stokes, J., Need, A., Burke, J. R., Welsh-Bohmer, K. A., \& Cabeza, R. (2010). Temporal lobe functional activity and connectivity in young adult APOE varepsilon4 carriers. Alzheimers Dement, 6(4), 303-311. doi:

10.1016/j.jalz.2009.07.003 
Desai, M. A., \& Conn, P. J. (1991). Excitatory effects of ACPD receptor activation in the hippocampus are mediated by direct effects on pyramidal cells and blockade of synaptic inhibition. J Neurophysiol, 66(1), 40-52.

Desai, M. A., Smith, T. S., \& Conn, P. J. (1992). Multiple metabotropic glutamate receptors regulate hippocampal function. Synapse, 12(3), 206-213. doi: 10.1002/syn.890120305

Devan, B. D., Stouffer, E. M., Petri, H. L., McDonald, R. J., \& Olds, J. L. (2003). Partial reinforcement across trials impairs escape performance but spares place learning in the water maze. Behav Brain Res, 141(2), 91-104.

DeVos, S. L., Goncharoff, D. K., Chen, G., Kebodeaux, C. S., Yamada, K., Stewart, F. R., . . . Miller, T. M. (2013). Antisense reduction of tau in adult mice protects against seizures. $J$ Neurosci, 33(31), 12887-12897. doi: 10.1523/jneurosci.2107-13.2013

Diamond, J. S. (2001). Neuronal glutamate transporters limit activation of NMDA receptors by neurotransmitter spillover on CA1 pyramidal cells. J Neurosci, 21(21), 8328-8338.

Diamond, J. S. (2005). Deriving the glutamate clearance time course from transporter currents in CA1 hippocampal astrocytes: transmitter uptake gets faster during development. $J$ Neurosci, 25(11), 2906-2916. doi: 10.1523/jneurosci.5125-04.2005

Dickerson, B. C., Salat, D. H., Greve, D. N., Chua, E. F., Rand-Giovannetti, E., Rentz, D. M., . . . Sperling, R. A. (2005). Increased hippocampal activation in mild cognitive impairment compared to normal aging and AD. Neurology, 65(3), 404-411. doi: 10.1212/01.wnl.0000171450.97464.49

Dingledine, R. (1983). N-methyl aspartate activates voltage-dependent calcium conductance in rat hippocampal pyramidal cells. J Physiol, 343, 385-405. 
Du, A. T., Schuff, N., Kramer, J. H., Ganzer, S., Zhu, X. P., Jagust, W. J., . . W Weiner, M. W. (2004). Higher atrophy rate of entorhinal cortex than hippocampus in AD. Neurology, $62(3), 422-427$

Egebjerg, J., Bettler, B., Hermans-Borgmeyer, I., \& Heinemann, S. (1991). Cloning of a cDNA for a glutamate receptor subunit activated by kainate but not AMPA. Nature, 351(6329), 745-748. doi: 10.1038/351745a0

Eimerl, S., \& Schramm, M. (1994). The quantity of calcium that appears to induce neuronal death. J Neurochem, 62(3), 1223-1226.

Ferrarese, C., Zoia, C., Pecora, N., Piolti, R., Frigo, M., Bianchi, G., . . . Frattola, L. (1999). Reduced platelet glutamate uptake in Parkinson's disease. J Neural Transm, 106(7-8), 685-692.

Filippini, N., MacIntosh, B. J., Hough, M. G., Goodwin, G. M., Frisoni, G. B., Smith, S. M., . . Mackay, C. E. (2009). Distinct patterns of brain activity in young carriers of the APOEepsilon4 allele. Proc Natl Acad Sci U S A, 106(17), 7209-7214. doi: 10.1073/pnas.0811879106

Fogal, B., Li, J., Lobner, D., McCullough, L. D., \& Hewett, S. J. (2007). System x(c)- activity and astrocytes are necessary for interleukin-1 beta-mediated hypoxic neuronal injury. $J$ Neurosci, 27(38), 10094-10105. doi: 10.1523/jneurosci.2459-07.2007

Forman, M. S., Lal, D., Zhang, B., Dabir, D. V., Swanson, E., Lee, V. M., \& Trojanowski, J. Q. (2005). Transgenic mouse model of tau pathology in astrocytes leading to nervous system degeneration. J Neurosci, 25(14), 3539-3550. doi: 10.1523/jneurosci.0081-05.2005 
Fox, G. B., Fan, L., LeVasseur, R. A., \& Faden, A. I. (1998). Effect of traumatic brain injury on mouse spatial and nonspatial learning in the Barnes circular maze. J Neurotrauma, 15(12), 1037-1046.

Friedemann, M. N., \& Gerhardt, G. A. (1992). Regional effects of aging on dopaminergic function in the Fischer-344 rat. Neurobiol Aging, 13(2), 325-332.

Fukaya, M., Hayashi, Y., \& Watanabe, M. (2005). NR2 to NR3B subunit switchover of NMDA receptors in early postnatal motoneurons. Eur J Neurosci, 21(5), 1432-1436. doi: 10.1111/j.1460-9568.2005.03957.x

Fukutani, Y., Kobayashi, K., Nakamura, I., Watanabe, K., Isaki, K., \& Cairns, N. J. (1995). Neurons, intracellular and extracellular neurofibrillary tangles in subdivisions of the hippocampal cortex in normal ageing and Alzheimer's disease. Neurosci Lett, 200(1), 5760.

Gegelashvili, G., Danbolt, N. C., \& Schousboe, A. (1997). Neuronal soluble factors differentially regulate the expression of the GLT1 and GLAST glutamate transporters in cultured astroglia. J Neurochem, 69(6), 2612-2615.

Ghose, S., Wroblewska, B., Corsi, L., Grayson, D. R., De Blas, A. L., Vicini, S., \& Neale, J. H. (1997). N-acetylaspartylglutamate stimulates metabotropic glutamate receptor 3 to regulate expression of the GABA(A) alpha6 subunit in cerebellar granule cells. $J$ Neurochem, 69(6), 2326-2335.

Gibbs, M. E., O'Dowd, B. S., Hertz, L., Robinson, S. R., Sedman, G. L., \& Ng, K. T. (1996). Inhibition of glutamine synthetase activity prevents memory consolidation. Brain Res Cogn Brain Res, 4(1), 57-64. 
Gil-Sanz, C., Delgado-Garcia, J. M., Fairen, A., \& Gruart, A. (2008). Involvement of the mGluR1 receptor in hippocampal synaptic plasticity and associative learning in behaving mice. Cereb Cortex, 18(7), 1653-1663. doi: 10.1093/cercor/bhm193

Gomez-Isla, T., Price, J. L., McKeel, D. W., Jr., Morris, J. C., Growdon, J. H., \& Hyman, B. T. (1996). Profound loss of layer II entorhinal cortex neurons occurs in very mild Alzheimer's disease. J Neurosci, 16(14), 4491-4500.

Gong, Q. Z., Delahunty, T. M., Hamm, R. J., \& Lyeth, B. G. (1995). Metabotropic glutamate antagonist, MCPG, treatment of traumatic brain injury in rats. Brain Res, 700(1-2), 299302.

Grady, C. L., McIntosh, A. R., Beig, S., Keightley, M. L., Burian, H., \& Black, S. E. (2003). Evidence from functional neuroimaging of a compensatory prefrontal network in Alzheimer's disease. J Neurosci, 23(3), 986-993.

Gras, C., Herzog, E., Bellenchi, G. C., Bernard, V., Ravassard, P., Pohl, M., . . El Mestikawy, S. (2002). A third vesicular glutamate transporter expressed by cholinergic and serotoninergic neurons. J Neurosci, 22(13), 5442-5451.

Greenamyre, J. T., \& Young, A. B. (1989). Excitatory amino acids and Alzheimer's disease. Neurobiol Aging, 10(5), 593-602.

Greene, J. G., Borges, K., \& Dingledine, R. (2009). Quantitative transcriptional neuroanatomy of the rat hippocampus: evidence for wide-ranging, pathway-specific heterogeneity among three principal cell layers. Hippocampus, 19(3), 253-264. doi: 10.1002/hipo.20502 Hamalainen, A., Pihlajamaki, M., Tanila, H., Hanninen, T., Niskanen, E., Tervo, S., . . . Soininen, H. (2007). Increased fMRI responses during encoding in mild cognitive 
impairment. Neurobiol Aging, 28(12), 1889-1903. doi:

10.1016/j.neurobiolaging.2006.08.008

Hardingham, G. E. (2006). Pro-survival signalling from the NMDA receptor. Biochem Soc Trans, 34(Pt 5), 936-938. doi: 10.1042/bst0340936

Hardingham, G. E., \& Bading, H. (2010a). Synaptic versus extrasynaptic NMDA receptor signalling: implications for neurodegenerative disorders. Nat Rev Neurosci, 11(10), 682696. doi: $10.1038 / \mathrm{nrn} 2911$

Hardingham, G. E., \& Bading, H. (2010b). Synaptic versus extrasynaptic NMDA receptor signalling: implications for neurodegenerative disorders. Nat Rev Neurosci., 11(10), 682696. Epub 2010 Sep 2015.

Hardingham, G. E., Fukunaga, Y., \& Bading, H. (2002). Extrasynaptic NMDARs oppose synaptic NMDARs by triggering CREB shut-off and cell death pathways. Nat Neurosci, 5(5), 405-414. doi: 10.1038/nn835

Harrison, F. E., Hosseini, A. H., \& McDonald, M. P. (2009). Endogenous anxiety and stress responses in water maze and Barnes maze spatial memory tasks. Behav Brain Res, 198(1), 247-251. doi: 10.1016/j.bbr.2008.10.015

Harvey, B. K., Airavaara, M., Hinzman, J., Wires, E. M., Chiocco, M. J., Howard, D. B., . . Wang, Y. (2011). Targeted over-expression of glutamate transporter 1 (GLT-1) reduces ischemic brain injury in a rat model of stroke. PLoS One, 6(8), e22135. doi: 10.1371/journal.pone.0022135

Haugeto, O., Ullensvang, K., Levy, L. M., Chaudhry, F. A., Honore, T., Nielsen, M., . . Danbolt, N. C. (1996). Brain glutamate transporter proteins form homomultimers. J Biol Chem, 271(44), 27715-27722. 
Hensley, K., Carney, J. M., Mattson, M. P., Aksenova, M., Harris, M., Wu, J. F., . . Butterfield, D. A. (1994). A model for beta-amyloid aggregation and neurotoxicity based on free radical generation by the peptide: relevance to Alzheimer disease. Proc Natl Acad Sci U $S$ A, 91(8), 3270-3274.

Herb, A., Burnashev, N., Werner, P., Sakmann, B., Wisden, W., \& Seeburg, P. H. (1992). The KA-2 subunit of excitatory amino acid receptors shows widespread expression in brain and forms ion channels with distantly related subunits. Neuron, 8(4), 775-785.

Herman, M. A., \& Jahr, C. E. (2007). Extracellular glutamate concentration in hippocampal slice. J Neurosci, 27(36), 9736-9741. doi: 10.1523/jneurosci.3009-07.2007

Herzog, E., Takamori, S., Jahn, R., Brose, N., \& Wojcik, S. M. (2006). Synaptic and vesicular co-localization of the glutamate transporters VGLUT1 and VGLUT2 in the mouse hippocampus. J Neurochem, 99(3), 1011-1018. doi: 10.1111/j.1471-4159.2006.04144.x

Hetman, M., \& Kharebava, G. (2006). Survival signaling pathways activated by NMDA receptors. Curr Top Med Chem, 6(8), 787-799.

Hillered, L., Vespa, P. M., \& Hovda, D. A. (2005). Translational neurochemical research in acute human brain injury: the current status and potential future for cerebral microdialysis. J Neurotrauma, 22(1), 3-41. doi: 10.1089/neu.2005.22.3

Hinzman, J. M., Thomas, T. C., Burmeister, J. J., Quintero, J. E., Huettl, P., Pomerleau, F., . . Lifshitz, J. (2010). Diffuse brain injury elevates tonic glutamate levels and potassiumevoked glutamate release in discrete brain regions at two days post-injury: an enzymebased microelectrode array study. J Neurotrauma, 27(5), 889-899. doi: 10.1089/neu.2009.1238 
Hinzman, J. M., Thomas, T. C., Quintero, J. E., Gerhardt, G. A., \& Lifshitz, J. (2012).

Disruptions in the regulation of extracellular glutamate by neurons and glia in the rat striatum two days after diffuse brain injury. J Neurotrauma, 29(6), 1197-1208. doi: 10.1089/neu.2011.2261

Hollmann, M., Hartley, M., \& Heinemann, S. (1991). Ca2+ permeability of KA-AMPA--gated glutamate receptor channels depends on subunit composition. Science, 252(5007), 851853.

Holth, J. K., Bomben, V. C., Reed, J. G., Inoue, T., Younkin, L., Younkin, S. G., . . Noebels, J. L. (2013). Tau loss attenuates neuronal network hyperexcitability in mouse and Drosophila genetic models of epilepsy. J Neurosci, 33(4), 1651-1659. doi: 10.1523/jneurosci.3191-12.2013

Hong, Y. K., Lee, S., Park, S. H., Lee, J. H., Han, S. Y., Kim, S. T., . . Cho, K. S. (2012). Inhibition of JNK/dFOXO pathway and caspases rescues neurological impairments in Drosophila Alzheimer's disease model. Biochem Biophys Res Commun, 419(1), 49-53. doi: 10.1016/j.bbrc.2012.01.122

Hoover, B. R., Reed, M. N., Su, J., Penrod, R. D., Kotilinek, L. A., Grant, M. K., . . Liao, D. (2010). Tau mislocalization to dendritic spines mediates synaptic dysfunction independently of neurodegeneration. Neuron, 68(6), 1067-1081. doi:

10.1016/j.neuron.2010.11.030

Hsia, A. Y., Masliah, E., McConlogue, L., Yu, G. Q., Tatsuno, G., Hu, K., . . Mucke, L. (1999). Plaque-independent disruption of neural circuits in Alzheimer's disease mouse models. Proc Natl Acad Sci U S A, 96(6), 3228-3233. 
Impey, S., Smith, D. M., Obrietan, K., Donahue, R., Wade, C., \& Storm, D. R. (1998).

Stimulation of cAMP response element (CRE)-mediated transcription during contextual learning. Nat Neurosci, 1(7), 595-601. doi: 10.1038/2830

Iqbal, K., Liu, F., Gong, C. X., \& Grundke-Iqbal, I. (2010). Tau in Alzheimer disease and related tauopathies. Curr Alzheimer Res, 7(8), 656-664.

Ittner, Lars M., Ke, Yazi D., Delerue, Fabien, Bi, Mian, Gladbach, Amadeus, van Eersel, Janet, . . . G^tz, J,rgen. (2010). Dendritic function of tau mediates amyloid-[beta] toxicity in Alzheimer's disease mouse models. Cell, 142(3), 387-397.

Ivanov, A., Pellegrino, C., Rama, S., Dumalska, I., Salyha, Y., Ben-Ari, Y., \& Medina, I. (2006). Opposing role of synaptic and extrasynaptic NMDA receptors in regulation of the extracellular signal-regulated kinases (ERK) activity in cultured rat hippocampal neurons. J Physiol, 572(Pt 3), 789-798. doi: 10.1113/jphysiol.2006.105510

Jabaudon, D., Shimamoto, K., Yasuda-Kamatani, Y., Scanziani, M., Gahwiler, B. H., \& Gerber, U. (1999). Inhibition of uptake unmasks rapid extracellular turnover of glutamate of nonvesicular origin. Proc Natl Acad Sci U S A, 96(15), 8733-8738.

Jamsa, A., Backstrom, A., Gustafsson, E., Dehvari, N., Hiller, G., Cowburn, R. F., \& Vasange, M. (2006). Glutamate treatment and p25 transfection increase Cdk5 mediated tau phosphorylation in SH-SY5Y cells. Biochem Biophys Res Commun, 345(1), 324-331. doi: 10.1016/j.bbrc.2006.04.032

Jaquins-Gerstl, A., \& Michael, A. C. (2009). Comparison of the brain penetration injury associated with microdialysis and voltammetry. J Neurosci Methods, 183(2), 127-135. doi: 10.1016/j.jneumeth.2009.06.023 
Johnson, J. W., \& Ascher, P. (1987). Glycine potentiates the NMDA response in cultured mouse brain neurons. Nature, 325(6104), 529-531. doi: 10.1038/325529a0

Kanai, Y., \& Hediger, M. A. (1992). Primary structure and functional characterization of a highaffinity glutamate transporter. Nature, 360(6403), 467-471. doi: 10.1038/360467a0

Keinanen, K., Wisden, W., Sommer, B., Werner, P., Herb, A., Verdoorn, T. A., . . Seeburg, P. H. (1990). A family of AMPA-selective glutamate receptors. Science, 249(4968), 556560.

Kew, J. N., \& Kemp, J. A. (2005). Ionotropic and metabotropic glutamate receptor structure and pharmacology. Psychopharmacology (Berl), 179(1), 4-29. doi: 10.1007/s00213-005$2200-\mathrm{Z}$

Kinoshita, A., Shigemoto, R., Ohishi, H., van der Putten, H., \& Mizuno, N. (1998). Immunohistochemical localization of metabotropic glutamate receptors, mGluR7a and mGluR7b, in the central nervous system of the adult rat and mouse: a light and electron microscopic study. J Comp Neurol, 393(3), 332-352.

Kleckner, N. W., \& Dingledine, R. (1988). Requirement for glycine in activation of NMDAreceptors expressed in Xenopus oocytes. Science, 241(4867), 835-837.

Koh, M. T., Haberman, R. P., Foti, S., McCown, T. J., \& Gallagher, M. (2010). Treatment strategies targeting excess hippocampal activity benefit aged rats with cognitive impairment. Neuropsychopharmacology, 35(4), 1016-1025. doi: 10.1038/npp.2009.207

Kong, Qingran, Wu, Meiling, Huan, Yanjun, Zhang, Li, Liu, Haiyan, Bou, Gerelchimeg, ... Liu, Zhonghua. (2009). Transgene Expression Is Associated with Copy Number and Cytomegalovirus Promoter Methylation in Transgenic Pigs. PLoS ONE, 4(8), e6679. doi: 10.1371/journal.pone.0006679 
Krebs, H. A., \& Johnson, W. A. (1937). Metabolism of ketonic acids in animal tissues. Biochem $J, 31(4), 645-660$.

Krystal, J. H., D'Souza, D. C., Petrakis, I. L., Belger, A., Berman, R. M., Charney, D. S., . . . Madonick, S. (1999). NMDA agonists and antagonists as probes of glutamatergic dysfunction and pharmacotherapies in neuropsychiatric disorders. Harv Rev Psychiatry, $7(3), 125-143$.

Kutsuwada, T., Kashiwabuchi, N., Mori, H., Sakimura, K., Kushiya, E., Araki, K., . . . et al. (1992). Molecular diversity of the NMDA receptor channel. Nature, 358(6381), 36-41. doi: $10.1038 / 358036 \mathrm{a} 0$

Le Meur, K., Galante, M., Angulo, M. C., \& Audinat, E. (2007). Tonic activation of NMDA receptors by ambient glutamate of non-synaptic origin in the rat hippocampus. $J$ Physiol, 580(Pt. 2), 373-383. doi: 10.1113/jphysiol.2006.123570

Lehre, K. P., Davanger, S., \& Danbolt, N. C. (1997). Localization of the glutamate transporter protein GLAST in rat retina. Brain Res, 744(1), 129-137.

Lehre, K. P., Levy, L. M., Ottersen, O. P., Storm-Mathisen, J., \& Danbolt, N. C. (1995). Differential expression of two glial glutamate transporters in the rat brain: quantitative and immunocytochemical observations. J Neurosci, $15(3 \mathrm{Pt}$ 1), 1835-1853.

Lerma, J., Herranz, A. S., Herreras, O., Abraira, V., \& Martin del Rio, R. (1986). In vivo determination of extracellular concentration of amino acids in the rat hippocampus. A method based on brain dialysis and computerized analysis. Brain Res, 384(1), 145-155.

Leutgeb, Stefan, Leutgeb, Jill K., Treves, Alessandro, Moser, May-Britt, \& Moser, Edvard I. (2004). Distinct Ensemble Codes in Hippocampal Areas CA3 and CA1. Science, 305(5688), 1295-1298. doi: 10.1126/science.1100265 
Leveille, F., Papadia, S., Fricker, M., Bell, K. F., Soriano, F. X., Martel, M. A., . . Hardingham, G. E. (2010). Suppression of the intrinsic apoptosis pathway by synaptic activity. $J$ Neurosci, 30(7), 2623-2635. doi: 10.1523/jneurosci.5115-09.2010

Li, D., Herault, K., Silm, K., Evrard, A., Wojcik, S., Oheim, M., . . Ropert, N. (2013). Lack of evidence for vesicular glutamate transporter expression in mouse astrocytes. $J$ Neurosci, 33(10), 4434-4455. doi: 10.1523/jneurosci.3667-12.2013

Li, S., Mallory, M., Alford, M., Tanaka, S., \& Masliah, E. (1997). Glutamate transporter alterations in Alzheimer disease are possibly associated with abnormal APP expression. $J$ Neuropathol Exp Neurol, 56(8), 901-911.

Liao, G., Zhou, M., Cheung, S., Galeano, J., Nguyen, N., Baudry, M., \& Bi, X. (2009). Reduced early hypoxic/ischemic brain damage is associated with increased GLT-1 levels in mice expressing mutant (P301L) human tau. Brain Res, 1247, 159-170. doi: 10.1016/j.brainres.2008.10.022

Lieth, E., LaNoue, K. F., Antonetti, D. A., \& Ratz, M. (2000). Diabetes reduces glutamate oxidation and glutamine synthesis in the retina. The Penn State Retina Research Group. Exp Eye Res, 70(6), 723-730. doi: 10.1006/exer.2000.0840

Liu, B., Wang, S., Brenner, M., Paton, J. F., \& Kasparov, S. (2008). Enhancement of cellspecific transgene expression from a Tet-Off regulatory system using a transcriptional amplification strategy in the rat brain. J Gene Med, 10(5), 583-592. doi: $10.1002 / j g m .1178$

Liu, L., Drouet, V., Wu, J. W., Witter, M. P., Small, S. A., Clelland, C., \& Duff, K. (2012). Trans-synaptic spread of tau pathology in vivo. PLoS One, 7(2), e31302. doi: 10.1371/journal.pone.0031302 
Lo, E. H., Dalkara, T., \& Moskowitz, M. A. (2003). Mechanisms, challenges and opportunities in stroke. Nat Rev Neurosci, 4(5), 399-415. doi: 10.1038/nrn1106

Lujan, R., Nusser, Z., Roberts, J. D., Shigemoto, R., \& Somogyi, P. (1996). Perisynaptic location of metabotropic glutamate receptors mGluR1 and mGluR5 on dendrites and dendritic spines in the rat hippocampus. Eur J Neurosci, 8(7), 1488-1500.

Lyon, L., Kew, J. N., Corti, C., Harrison, P. J., \& Burnet, P. W. (2008). Altered hippocampal expression of glutamate receptors and transporters in GRM2 and GRM3 knockout mice. Synapse, 62(11), 842-850. doi: 10.1002/syn.20553

MacDermott, A. B., Mayer, M. L., Westbrook, G. L., Smith, S. J., \& Barker, J. L. (1986). NMDA-receptor activation increases cytoplasmic calcium concentration in cultured spinal cord neurones. Nature, 321(6069), 519-522. doi: 10.1038/321519a0

Mackenzie, I. R., \& Miller, L. A. (1994). Senile plaques in temporal lobe epilepsy. Acta Neuropathol, 87(5), 504-510.

Maragakis, N. J., \& Rothstein, J. D. (2004). Glutamate transporters: animal models to neurologic disease. Neurobiol Dis, 15(3), 461-473. doi: 10.1016/j.nbd.2003.12.007

Martinez-Hernandez, A., Bell, K. P., \& Norenberg, M. D. (1977). Glutamine synthetase: glial localization in brain. Science, 195(4284), 1356-1358.

Masliah, E., Alford, M., Mallory, M., Rockenstein, E., Moechars, D., \& Van Leuven, F. (2000). Abnormal glutamate transport function in mutant amyloid precursor protein transgenic mice. Exp Neurol, 163(2), 381-387. doi: 10.1006/exnr.2000.7386

Massie, A., Schallier, A., Mertens, B., Vermoesen, K., Bannai, S., Sato, H., . . Michotte, Y. (2008). Time-dependent changes in striatal xCT protein expression in hemi-Parkinson rats. Neuroreport, 19(16), 1589-1592. doi: 10.1097/WNR.0b013e328312181c 
Massie, A., Schallier, A., Vermoesen, K., Arckens, L., \& Michotte, Y. (2010). Biphasic and bilateral changes in striatal VGLUT1 and 2 protein expression in hemi-Parkinson rats. Neurochem Int, 57(2), 111-118. doi: 10.1016/j.neuint.2010.04.019

Masu, M., Tanabe, Y., Tsuchida, K., Shigemoto, R., \& Nakanishi, S. (1991). Sequence and expression of a metabotropic glutamate receptor. Nature, 349(6312), 760-765. doi: $10.1038 / 349760 \mathrm{a} 0$

Mattinson, C. E., Burmeister, J. J., Quintero, J. E., Pomerleau, F., Huettl, P., \& Gerhardt, G. A. (2011). Tonic and phasic release of glutamate and acetylcholine neurotransmission in sub-regions of the rat prefrontal cortex using enzyme-based microelectrode arrays. $J$ Neurosci Methods, 202(2), 199-208. doi: 10.1016/j.jneumeth.2011.08.020

Mayford, M., Bach, M. E., Huang, Y. Y., Wang, L., Hawkins, R. D., \& Kandel, E. R. (1996). Control of memory formation through regulated expression of a CaMKII transgene. Science, 274(5293), 1678-1683.

McAfoose, J., Koerner, H., \& Baune, B. T. (2009). The effects of TNF deficiency on age-related cognitive performance. Psychoneuroendocrinology, 34(4), 615-619. doi: 10.1016/j.psyneuen.2008.10.006

McKenna, M. C., \& Sonnewald, U. (2005). GABA alters the metabolic fate of [U-13C]glutamate in cultured cortical astrocytes. J Neurosci Res, 79(1-2), 81-87. doi: 10.1002/jnr.20309

McKenna, M. C., Sonnewald, U., Huang, X., Stevenson, J., \& Zielke, H. R. (1996). Exogenous glutamate concentration regulates the metabolic fate of glutamate in astrocytes. $J$ Neurochem, 66(1), 386-393.

McLay, R. N., Freeman, S. M., \& Zadina, J. E. (1998). Chronic corticosterone impairs memory performance in the Barnes maze. Physiol Behav, 63(5), 933-937. 
Miele, M., Berners, M., Boutelle, M. G., Kusakabe, H., \& Fillenz, M. (1996). The determination of the extracellular concentration of brain glutamate using quantitative microdialysis. Brain Res, 707(1), 131-133.

Movsesyan, V. A., \& Faden, A. I. (2006). Neuroprotective effects of selective group II mGluR activation in brain trauma and traumatic neuronal injury. $J$ Neurotrauma, 23(2), 117-127. doi: $10.1089 /$ neu.2006.23.117

Mucke, L., Masliah, E., Yu, G. Q., Mallory, M., Rockenstein, E. M., Tatsuno, G., . . McConlogue, L. (2000). High-level neuronal expression of abeta 1-42 in wild-type human amyloid protein precursor transgenic mice: synaptotoxicity without plaque formation. J Neurosci, 20(11), 4050-4058.

Nakanishi, S. (1992). Molecular diversity of glutamate receptors and implications for brain function. Science, 258(5082), 597-603.

Nath, S., Agholme, L., Kurudenkandy, F. R., Granseth, B., Marcusson, J., \& Hallbeck, M. (2012). Spreading of neurodegenerative pathology via neuron-to-neuron transmission of beta-amyloid. J Neurosci, 32(26), 8767-8777. doi: 10.1523/jneurosci.0615-12.2012

Nickell, J., Salvatore, M. F., Pomerleau, F., Apparsundaram, S., \& Gerhardt, G. A. (2007). Reduced plasma membrane surface expression of GLAST mediates decreased glutamate regulation in the aged striatum. Neurobiol Aging, 28(11), 1737-1748. doi:

10.1016/j.neurobiolaging.2006.07.015

Nilsson, A., Duan, J., Mo-Boquist, L. L., Benedikz, E., \& Sundstrom, E. (2007). Characterisation of the human NMDA receptor subunit NR3A glycine binding site. Neuropharmacology, 52(4), 1151-1159. doi: 10.1016/j.neuropharm.2006.12.002 
Nimchinsky, E. A., Yasuda, R., Oertner, T. G., \& Svoboda, K. (2004). The number of glutamate receptors opened by synaptic stimulation in single hippocampal spines. J Neurosci, 24(8), 2054-2064. doi: 10.1523/jneurosci.5066-03.2004

Norenberg, M. D., \& Martinez-Hernandez, A. (1979). Fine structural localization of glutamine synthetase in astrocytes of rat brain. Brain Res, 161(2), 303-310.

Nowak, L., Bregestovski, P., Ascher, P., Herbet, A., \& Prochiantz, A. (1984). Magnesium gates glutamate-activated channels in mouse central neurones. Nature, 307(5950), 462-465.

Obrenovitch, T. P., Urenjak, J., Zilkha, E., \& Jay, T. M. (2000). Excitotoxicity in neurological disorders--the glutamate paradox. Int J Dev Neurosci, 18(2-3), 281-287.

Okamoto, S., Pouladi, M. A., Talantova, M., Yao, D., Xia, P., Ehrnhoefer, D. E., . . Lipton, S. A. (2009). Balance between synaptic versus extrasynaptic NMDA receptor activity influences inclusions and neurotoxicity of mutant huntingtin. Nat Med, 15(12), 14071413. doi: $10.1038 / \mathrm{nm} .2056$

Olney, J. W. (1969). Brain lesions, obesity, and other disturbances in mice treated with monosodium glutamate. Science, 164(3880), 719-721.

Olney, J. W., \& de Gubareff, T. (1978). Glutamate neurotoxicity and Huntington's chorea. Nature, 271(5645), 557-559.

Olney, J. W., Price, M. T., Samson, L., \& Labruyere, J. (1986). The role of specific ions in glutamate neurotoxicity. Neurosci Lett, 65(1), 65-71.

Palop, J. J., Chin, J., \& Mucke, L. (2006). A network dysfunction perspective on neurodegenerative diseases. Nature, 443(7113), 768-773. doi: 10.1038/nature05289 
Pampliega, O., Domercq, M., Soria, F. N., Villoslada, P., Rodriguez-Antiguedad, A., \& Matute, C. (2011). Increased expression of cystine/glutamate antiporter in multiple sclerosis. $J$ Neuroinflammation, 8, 63. doi: 10.1186/1742-2094-8-63

Papadia, S., Soriano, F. X., Leveille, F., Martel, M. A., Dakin, K. A., Hansen, H. H., . . . Hardingham, G. E. (2008). Synaptic NMDA receptor activity boosts intrinsic antioxidant defenses. Nat Neurosci, 11(4), 476-487. doi: 10.1038/nn2071

Parsons, C. G., Stoffler, A., \& Danysz, W. (2007). Memantine: a NMDA receptor antagonist that improves memory by restoration of homeostasis in the glutamatergic system--too little activation is bad, too much is even worse. Neuropharmacology, 53(6), 699-723. doi: 10.1016/j.neuropharm.2007.07.013

Petralia, R. S., Sans, N., Wang, Y. X., \& Wenthold, R. J. (2005). Ontogeny of postsynaptic density proteins at glutamatergic synapses. Mol Cell Neurosci, 29(3), 436-452. doi: 10.1016/j.mcn.2005.03.013

Petroni, D., Tsai, J., Mondal, D., \& George, W. (2011). Attenuation of low dose methylmercury and glutamate induced-cytotoxicity and tau phosphorylation by an N-methyl-D-aspartate antagonist in human neuroblastoma (SHSY5Y) cells. Environ Toxicol. doi: 10.1002/tox.20765

Pettit, D. L., \& Augustine, G. J. (2000). Distribution of functional glutamate and GABA receptors on hippocampal pyramidal cells and interneurons. J Neurophysiol, 84(1), 28-38.

Plaitakis, A., Flessas, P., Natsiou, A. B., \& Shashidharan, P. (1993). Glutamate dehydrogenase deficiency in cerebellar degenerations: clinical, biochemical and molecular genetic aspects. Can J Neurol Sci, 20 Suppl 3, S109-116. 
Planel, E., Miyasaka, T., Launey, T., Chui, D. H., Tanemura, K., Sato, S., . . Takashima, A. (2004). Alterations in glucose metabolism induce hypothermia leading to tau hyperphosphorylation through differential inhibition of kinase and phosphatase activities: implications for Alzheimer's disease. J Neurosci, 24(10), 2401-2411. doi: 10.1523/jneurosci.5561-03.2004

Pompl, P. N., Mullan, M. J., Bjugstad, K., \& Arendash, G. W. (1999). Adaptation of the circular platform spatial memory task for mice: use in detecting cognitive impairment in the APP(SW) transgenic mouse model for Alzheimer's disease. J Neurosci Methods, 87(1), $87-95$

Popoli, M., Yan, Z., McEwen, B. S., \& Sanacora, G. (2012). The stressed synapse: the impact of stress and glucocorticoids on glutamate transmission. Nat Rev Neurosci, 13(1), 22-37. doi: $10.1038 / \mathrm{nrn} 3138$

Poschel, B., Wroblewska, B., Heinemann, U., \& Manahan-Vaughan, D. (2005). The metabotropic glutamate receptor mGluR3 is critically required for hippocampal longterm depression and modulates long-term potentiation in the dentate gyrus of freely moving rats. Cereb Cortex, 15(9), 1414-1423. doi: 10.1093/cercor/bhi022

Qin, S., Colin, C., Hinners, I., Gervais, A., Cheret, C., \& Mallat, M. (2006). System Xc- and apolipoprotein E expressed by microglia have opposite effects on the neurotoxicity of amyloid-beta peptide 1-40. J Neurosci, 26(12), 3345-3356. doi: 10.1523/jneurosci.518605.2006

Quiroz, Y. T., Budson, A. E., Celone, K., Ruiz, A., Newmark, R., Castrillon, G., .. . Stern, C. E. (2010). Hippocampal hyperactivation in presymptomatic familial Alzheimer's disease. Ann Neurol, 68(6), 865-875. doi: 10.1002/ana.22105 
Rae, C., Hare, N., Bubb, W. A., McEwan, S. R., Broer, A., McQuillan, J. A., . . Broer, S. (2003). Inhibition of glutamine transport depletes glutamate and GABA neurotransmitter pools: further evidence for metabolic compartmentation. J Neurochem, 85(2), 503-514.

Ramaharobandro, N., Borg, J., Mandel, P., \& Mark, J. (1982). Glutamine and glutamate transport in cultured neuronal and glial cells. Brain Res, 244(1), 113-121.

Ramsden, M., Kotilinek, L., Forster, C., Paulson, J., McGowan, E., SantaCruz, K., . . Ashe, K. H. (2005). Age-dependent neurofibrillary tangle formation, neuron loss, and memory impairment in a mouse model of human tauopathy (P301L). J Neurosci, 25(46), 1063710647. doi: 10.1523/jneurosci.3279-05.2005

Rebeck, G. W., Marzloff, K., \& Hyman, B. T. (1993). The pattern of NADPH-diaphorase staining, a marker of nitric oxide synthase activity, is altered in the perforant pathway terminal zone in Alzheimer's disease. Neurosci Lett, 152(1-2), 165-168.

Roberson, E. D., Halabisky, B., Yoo, J. W., Yao, J., Chin, J., Yan, F., . . Mucke, L. (2011). Amyloid-beta/Fyn-induced synaptic, network, and cognitive impairments depend on tau levels in multiple mouse models of Alzheimer's disease. J Neurosci, 31(2), 700-711. doi: 10.1523/jneurosci.4152-10.2011

Roberson, E. D., Scearce-Levie, K., Palop, J. J., Yan, F., Cheng, I. H., Wu, T., . . Mucke, L. (2007). Reducing endogenous tau ameliorates amyloid beta-induced deficits in an Alzheimer's disease mouse model. Science, 316(5825), 750-754. doi: 10.1126/science. 1141736

Robinson, S. R. (2000). Neuronal expression of glutamine synthetase in Alzheimer's disease indicates a profound impairment of metabolic interactions with astrocytes. Neurochem Int, 36(4-5), 471-482. 
Rothstein, J. D., Dykes-Hoberg, M., Pardo, C. A., Bristol, L. A., Jin, L., Kuncl, R. W., .. . Welty, D. F. (1996). Knockout of glutamate transporters reveals a major role for astroglial transport in excitotoxicity and clearance of glutamate. Neuron, 16(3), 675-686.

Rothstein, J. D., Van Kammen, M., Levey, A. I., Martin, L. J., \& Kuncl, R. W. (1995). Selective loss of glial glutamate transporter GLT-1 in amyotrophic lateral sclerosis. Ann Neurol, 38(1), 73-84. doi: 10.1002/ana.410380114

Sacaan, A. I., \& Schoepp, D. D. (1992). Activation of hippocampal metabotropic excitatory amino acid receptors leads to seizures and neuronal damage. Neurosci Lett, 139(1), 7782.

Saito, K., Elce, J. S., Hamos, J. E., \& Nixon, R. A. (1993). Widespread activation of calciumactivated neutral proteinase (calpain) in the brain in Alzheimer disease: a potential molecular basis for neuronal degeneration. Proc Natl Acad Sci U S A, 90(7), 2628-2632.

Sanchez, P. E., Zhu, L., Verret, L., Vossel, K. A., Orr, A. G., Cirrito, J. R., . . Mucke, L. (2012). Levetiracetam suppresses neuronal network dysfunction and reverses synaptic and cognitive deficits in an Alzheimer's disease model. Proc Natl Acad Sci U S A, 109(42), E2895-2903. doi: 10.1073/pnas.1121081109

Sansig, G., Bushell, T. J., Clarke, V. R., Rozov, A., Burnashev, N., Portet, C., . . van Der Putten, H. (2001). Increased seizure susceptibility in mice lacking metabotropic glutamate receptor 7. J Neurosci, 21(22), 8734-8745.

Santacruz, K., Lewis, J., Spires, T., Paulson, J., Kotilinek, L., Ingelsson, M., . . Ashe, K. H. (2005). Tau suppression in a neurodegenerative mouse model improves memory function. Science, 309(5733), 476-481. doi: 10.1126/science.1113694 
Savaskan, N. E., Heckel, A., Hahnen, E., Engelhorn, T., Doerfler, A., Ganslandt, O., .. . Eyupoglu, I. Y. (2008). Small interfering RNA-mediated xCT silencing in gliomas inhibits neurodegeneration and alleviates brain edema. Nat Med, 14(6), 629-632. doi: $10.1038 / \mathrm{nm} 1772$

Scanziani, M., Salin, P. A., Vogt, K. E., Malenka, R. C., \& Nicoll, R. A. (1997). Use-dependent increases in glutamate concentration activate presynaptic metabotropic glutamate receptors. Nature, 385(6617), 630-634. doi: 10.1038/385630a0

Schmidt, R. H., \& Grady, M. S. (1993). Regional patterns of blood-brain barrier breakdown following central and lateral fluid percussion injury in rodents. J Neurotrauma, 10(4), 415-430.

Schoepp, D. D. (2001). Unveiling the functions of presynaptic metabotropic glutamate receptors in the central nervous system. J Pharmacol Exp Ther, 299(1), 12-20.

Scott, H. L., Pow, D. V., Tannenberg, A. E., \& Dodd, P. R. (2002). Aberrant expression of the glutamate transporter excitatory amino acid transporter 1 (EAAT1) in Alzheimer's disease. J Neurosci, 22(3), RC206.

Semyanov, A., \& Kullmann, D. M. (2000). Modulation of GABAergic signaling among interneurons by metabotropic glutamate receptors. Neuron, 25(3), 663-672.

Serrano-Pozo, A., Frosch, M. P., Masliah, E., \& Hyman, B. T. (2011). Neuropathological alterations in Alzheimer disease. Cold Spring Harb Perspect Med, 1(1), a006189. doi: 10.1101/cshperspect.a006189

Shankar, G. M., Bloodgood, B. L., Townsend, M., Walsh, D. M., Selkoe, D. J., \& Sabatini, B. L. (2007). Natural oligomers of the Alzheimer amyloid-beta protein induce reversible 
synapse loss by modulating an NMDA-type glutamate receptor-dependent signaling pathway. J Neurosci, 27(11), 2866-2875. doi: 10.1523/jneurosci.4970-06.2007

Sheldon, A. L., \& Robinson, M. B. (2007). The role of glutamate transporters in neurodegenerative diseases and potential opportunities for intervention. Neurochem Int, 51(6-7), 333-355. doi: 10.1016/j.neuint.2007.03.012

Shigemoto, R., Nomura, S., Ohishi, H., Sugihara, H., Nakanishi, S., \& Mizuno, N. (1993). Immunohistochemical localization of a metabotropic glutamate receptor, mGluR5, in the rat brain. Neurosci Lett, 163(1), 53-57.

Small, S. A., Chawla, M. K., Buonocore, M., Rapp, P. R., \& Barnes, C. A. (2004). Imaging correlates of brain function in monkeys and rats isolates a hippocampal subregion differentially vulnerable to aging. Proc Natl Acad Sci U S A, 101(18), 7181-7186. doi: 10.1073/pnas.0400285101

Smith, C. D., Carney, J. M., Starke-Reed, P. E., Oliver, C. N., Stadtman, E. R., Floyd, R. A., \& Markesbery, W. R. (1991). Excess brain protein oxidation and enzyme dysfunction in normal aging and in Alzheimer disease. Proc Natl Acad Sci U S A, 88(23), 10540-10543.

Song, M. S., Rauw, G., Baker, G. B., \& Kar, S. (2008). Memantine protects rat cortical cultured neurons against beta-amyloid-induced toxicity by attenuating tau phosphorylation. Eur $J$ Neurosci, 28(10), 1989-2002. doi: 10.1111/j.1460-9568.2008.06498.x

Sotiropoulos, I., Catania, C., Pinto, L. G., Silva, R., Pollerberg, G. E., Takashima, A., . . . Almeida, O. F. (2011). Stress acts cumulatively to precipitate Alzheimer's disease-like tau pathology and cognitive deficits. J Neurosci, 31(21), 7840-7847. doi: 10.1523/jneurosci.0730-11.2011 
Sperling, R. A., Laviolette, P. S., O'Keefe, K., O'Brien, J., Rentz, D. M., Pihlajamaki, M., . . Johnson, K. A. (2009). Amyloid deposition is associated with impaired default network function in older persons without dementia. Neuron, 63(2), 178-188. doi: 10.1016/j.neuron.2009.07.003

Stephens, M. L., Quintero, J. E., Pomerleau, F., Huettl, P., \& Gerhardt, G. A. (2011). Age-related changes in glutamate release in the CA3 and dentate gyrus of the rat hippocampus. Neurobiol Aging, 32(5), 811-820. doi: 10.1016/j.neurobiolaging.2009.05.009

Storck, T., Schulte, S., Hofmann, K., \& Stoffel, W. (1992). Structure, expression, and functional analysis of a $\mathrm{Na}(+)$-dependent glutamate/aspartate transporter from rat brain. Proc Natl Acad Sci U S A, 89(22), 10955-10959.

Sudhof, T. C. (2004). The synaptic vesicle cycle. Annu Rev Neurosci, 27, 509-547. doi: 10.1146/annurev.neuro.26.041002.131412

Sugaya, K., Greene, R., Personett, D., Robbins, M., Kent, C., Bryan, D., . . McKinney, M. (1998). Septo-hippocampal cholinergic and neurotrophin markers in age-induced cognitive decline. Neurobiol Aging, 19(4), 351-361. doi: http://dx.doi.org/10.1016/S0197-4580(98)00072-4

Surmeier, D. J. (2007). Calcium, ageing, and neuronal vulnerability in Parkinson's disease. Lancet Neurol, 6(10), 933-938. doi: 10.1016/s1474-4422(07)70246-6

Sykova, E., Mazel, T., \& Simonova, Z. (1998). Diffusion constraints and neuron-glia interaction during aging. Exp Gerontol, 33(7-8), 837-851.

Szapiro, G., Galante, J. M., Barros, D. M., Levi de Stein, M., Vianna, M. R., Izquierdo, L. A., . . . Medina, J. H. (2002). Molecular mechanisms of memory retrieval. Neurochem Res, 27(11), 1491-1498. 
Takamori, S., Rhee, J. S., Rosenmund, C., \& Jahn, R. (2000). Identification of a vesicular glutamate transporter that defines a glutamatergic phenotype in neurons. Nature, 407(6801), 189-194. doi: 10.1038/35025070

Tan, W., Cao, X., Wang, J., Lv, H., Wu, B., \& Ma, H. (2010). Tau hyperphosphorylation is associated with memory impairment after exposure to $1.5 \%$ isoflurane without temperature maintenance in rats. Eur J Anaesthesiol, 27(9), 835-841. doi:

10.1097/EJA.0b013e32833a6561

Tang, C. M., Dichter, M., \& Morad, M. (1989). Quisqualate activates a rapidly inactivating high conductance ionic channel in hippocampal neurons. Science, 243(4897), 1474-1477.

Thai, D. R. (2002). Excitatory amino acid transporter EAAT-2 in tangle-bearing neurons in Alzheimer's disease. Brain Pathol, 12(4), 405-411.

Thal, D. R., Holzer, M., Rub, U., Waldmann, G., Gunzel, S., Zedlick, D., \& Schober, R. (2000). Alzheimer-related tau-pathology in the perforant path target zone and in the hippocampal stratum oriens and radiatum correlates with onset and degree of dementia. Exp Neurol, 163(1), 98-110. doi: 10.1006/exnr.2000.7380

Thies, W., \& Bleiler, L. (2013). 2013 Alzheimer's disease facts and figures. Alzheimers Dement, 9(2), 208-245. doi: 10.1016/j.jalz.2013.02.003

Thomas, T. C., Grandy, D. K., Gerhardt, G. A., \& Glaser, P. E. (2009). Decreased dopamine D4 receptor expression increases extracellular glutamate and alters its regulation in mouse striatum. Neuropsychopharmacology, 34(2), 436-445. doi: 10.1038/npp.2008.74

Tian, L., \& Kammermeier, P. J. (2006). G protein coupling profile of mGluR6 and expression of G alpha proteins in retinal ON bipolar cells. Vis Neurosci, 23(6), 909-916. doi: $10.1017 / \mathrm{s} 0952523806230268$ 
Timmer, N. M., Metaxas, A., van der Stelt, I., Kluijtmans, L. A., van Berckel, B. N., \& Verbeek, M. M. (2014). Cerebral level of vGlut1 is increased and level of glycine is decreased in TgSwDI mice. J Alzheimers Dis, 39(1), 89-101. doi: 10.3233/jad-130437

Trivedi, M. A., Schmitz, T. W., Ries, M. L., Hess, T. M., Fitzgerald, M. E., Atwood, C. S., . . Johnson, S. C. (2008). fMRI activation during episodic encoding and metacognitive appraisal across the lifespan: risk factors for Alzheimer's disease. Neuropsychologia, 46(6), 1667-1678. doi: 10.1016/j.neuropsychologia.2007.11.035

Trotti, D., Rolfs, A., Danbolt, N. C., Brown, R. H., Jr., \& Hediger, M. A. (1999). SOD1 mutants linked to amyotrophic lateral sclerosis selectively inactivate a glial glutamate transporter. Nat Neurosci, 2(9), 848. doi: 10.1038/12227

Uttara, B., Singh, A. V., Zamboni, P., \& Mahajan, R. T. (2009). Oxidative stress and neurodegenerative diseases: a review of upstream and downstream antioxidant therapeutic options. Curr Neuropharmacol, 7(1), 65-74. doi:

$10.2174 / 157015909787602823$

van de Pol, L. A., van der Flier, W. M., Korf, E. S., Fox, N. C., Barkhof, F., \& Scheltens, P. (2007). Baseline predictors of rates of hippocampal atrophy in mild cognitive impairment. Neurology, 69(15), 1491-1497. doi: 10.1212/01.wnl.0000277458.26846.96

von Engelhardt, J., Coserea, I., Pawlak, V., Fuchs, E. C., Kohr, G., Seeburg, P. H., \& Monyer, H. (2007). Excitotoxicity in vitro by NR2A- and NR2B-containing NMDA receptors. Neuropharmacology, 53(1), 10-17. doi: 10.1016/j.neuropharm.2007.04.015 Vossel, K. A., Beagle, A. J., Rabinovici, G. D., Shu, H., Lee, S. E., Naasan, G., . . Mucke, L. (2013). Seizures and epileptiform activity in the early stages of Alzheimer disease. JAMA Neurol, 70(9), 1158-1166. doi: 10.1001/jamaneurol.2013.136 
Waagepetersen, H. S., Qu, H., Sonnewald, U., Shimamoto, K., \& Schousboe, A. (2005). Role of glutamine and neuronal glutamate uptake in glutamate homeostasis and synthesis during vesicular release in cultured glutamatergic neurons. Neurochem Int, 47(1-2), 92-102. doi: 10.1016/j.neuint.2005.04.012

Wagey, R., Hu, J., Pelech, S. L., Raymond, L. A., \& Krieger, C. (2001). Modulation of NMDAmediated excitotoxicity by protein kinase C. J Neurochem, 78(4), 715-726.

Ward, N. S., \& Frackowiak, R. S. (2003). Age-related changes in the neural correlates of motor performance. Brain, 126(Pt 4), 873-888.

Watkins, J. C., \& Evans, R. H. (1981). Excitatory amino acid transmitters. Annu Rev Pharmacol Toxicol, 21, 165-204. doi: 10.1146/annurev.pa.21.040181.001121

Werner, P., Voigt, M., Keinanen, K., Wisden, W., \& Seeburg, P. H. (1991). Cloning of a putative high-affinity kainate receptor expressed predominantly in hippocampal CA3 cells. Nature, 351(6329), 742-744. doi: 10.1038/351742a0

West, M. J., Kawas, C. H., Martin, L. J., \& Troncoso, J. C. (2000). The CA1 region of the human hippocampus is a hot spot in Alzheimer's disease. Ann N Y Acad Sci, 908, 255-259.

West, M. J., \& Slomianka, L. (1998). Total number of neurons in the layers of the human entorhinal cortex. Hippocampus, 8(1), 69-82. doi: 10.1002/(SICI)10981063(1998)8:1\&lt;69::AID-HIPO7\&gt;3.0.CO;2-2

Wilson, I. A., Ikonen, S., Gallagher, M., Eichenbaum, H., \& Tanila, H. (2005). Age-associated alterations of hippocampal place cells are subregion specific. J Neurosci, 25(29), 68776886. doi: 10.1523/jneurosci.1744-05.2005 
Wilson, N. R., Kang, J., Hueske, E. V., Leung, T., Varoqui, H., Murnick, J. G., . . Liu, G. (2005). Presynaptic regulation of quantal size by the vesicular glutamate transporter VGLUT1. J Neurosci, 25(26), 6221-6234. doi: 10.1523/jneurosci.3003-04.2005

Xia, P., Chen, H. S., Zhang, D., \& Lipton, S. A. (2010). Memantine preferentially blocks extrasynaptic over synaptic NMDA receptor currents in hippocampal autapses. $J$ Neurosci, 30(33), 11246-11250. doi: 10.1523/jneurosci.2488-10.2010

Yamada, K., Holth, J. K., Liao, F., Stewart, F. R., Mahan, T. E., Jiang, H., . . Holtzman, D. M. (2014). Neuronal activity regulates extracellular tau in vivo. J Exp Med, 211(3), 387-393. doi: 10.1084/jem.20131685

Yassa, Michael A., Stark, Shauna M., Bakker, Arnold, Albert, Marilyn S., Gallagher, Michela, \& Stark, Craig E. L. (2010). High-resolution structural and functional MRI of hippocampal CA3 and dentate gyrus in patients with amnestic Mild Cognitive Impairment. Neuroimage, 51(3), 1242-1252. doi: http://dx.doi.org/10.1016/j.neuroimage.2010.03.040

Yokoi, M., Kobayashi, K., Manabe, T., Takahashi, T., Sakaguchi, I., Katsuura, G., . . Nakanishi, S. (1996). Impairment of hippocampal mossy fiber LTD in mice lacking mGluR2. Science, 273(5275), 645-647.

Zhang, Y., Kurup, P., Xu, J., Carty, N., Fernandez, S. M., Nygaard, H. B., . . Lombroso, P. J. (2010). Genetic reduction of striatal-enriched tyrosine phosphatase (STEP) reverses cognitive and cellular deficits in an Alzheimer's disease mouse model. Proc Natl Acad Sci U S A, 107(44), 19014-19019. doi: 10.1073/pnas.1013543107 
Zoia, C., Cogliati, T., Tagliabue, E., Cavaletti, G., Sala, G., Galimberti, G., . . Ferrarese, C. (2004). Glutamate transporters in platelets: EAAT1 decrease in aging and in Alzheimer's disease. Neurobiol Aging, 25(2), 149-157. 